\title{
Guidelines for the Assessment of Flavoring Substances in Foods on Health
}

\section{Full Report}

\author{
Food Safety Commission of Japan
}

The Food Safety Commission of Japan published the new guidelines for the risk assessment of flavoring substances on May 17, 2016. The new guidelines were established on the experiences on the risk assessment of "internationally commonly used flavors", referring to the approach for the risk assessment of flavorings in the Joint FAO/WHO Expert Committee on Food Additives (JECFA) and European Food Safety Authority (EFSA). From now on, the risk assessment of flavoring substances is conducted according to these guidelines.

\section{Chapter 1: General Provisions}

\section{Article 1: Background}

The Food Safety Commission of Japan (FSCJ) is encouraged to establish guidelines for the assessment of foodrelated hazards on human health (hereinafter referred to as "the risk assessment"), based on the Cabinet Decision (June 29, 2012), "Basic Matters" referred to in Article 21 paragraph (1) of the Food Safety Basic Act. "Guideline for Assessment of the Effect of Food on Human Health Regarding Food Additives" (May 27, 2010) is one of such guidelines*.

Guidelines for risk assessment are essential to enhance the scientific validity and fairness of assessments as well as to define the necessary data for the applicant, ensuring the transparency of assessment both within and outside Japan.

The risk assessment of internationally commonly used flavors has been conducted according to "Safety Assessment Procedures Regarding Internationally Commonly Used Flavors (the final report, the revised version) (November 4, 2003) $)^{1) " ~(h e r e i n a f t e r ~ r e f e r r e d ~ t o ~ a s ~ " t h e ~ f o r m e r ~ g u i d e l i n e s ") . ~}$

Published online: 22 December 2016

*The following guidelines have been established: "Standards for the Safety Assessment of Genetically Modified Foods (Seed Plants)" (January 29, 2004), "Stance on Assessment of the Effect of Food on Human Health Regarding Official Specifications of General Fertilizers" (March 18, 2004), "Standards for Safety Assessment of Food Additives Produced Using Genetically Modified Microorganisms" (March 25, 2004), "Stance on Safety Assessment of Genetically Modified Feed and Feed Additives" (May 6, 2004), "Assessment guideline for the Effect of Food on Human Health Regarding Antimicrobial-Resistant Bacteria Selected by Antimicrobial Use in Food Animals" (September 30, 2004), "Standards for Safety Assessment of Genetically Modified Foods (Microorganisms)" (June 26, 2008).

This is an English translation based on the original risk assessment report in Japanese (May 2016-FS/316/2016). Only original Japanese texts have legal effect.

The original full report is available in Japanese at http://www.fsc.go.jp/senmon/tenkabutu/index.data/kouryou-hyouka-shishin1.pdf Acknowledgement: FSCJ wishes to thank the members of Expert Committee on Food Additives for the preparation of the original full report.

Suggested citation: Food Safety Commission of JAPAN. Guidelines for the Assessment of Flavoring Substances in Foods on Health: Full Report. Food Safety. 2016; 4 (4): 142-168. doi:10.14252/foodsafetyfscj.2016017f 
In the risk assessment, needless to say, the effect on human must be emphasized. While ensuring human safety, it has been globally required to consider appropriate use of experimental animals in toxicological studies to the extent the scientific purpose is achieved.

Recently, a new risk assessment method for flavoring substances was proposed in a research report titled "Study on the Procedure for the Risk Assessment of Flavorings in Japan"4) (Principal Research Investigator: Takeshi Yamazaki, Professor of Jissen Women's University), supported by FSCJ as a Research and Survey Program. The new method was built on the experiences on the risk assessment of "internationally commonly used flavors," referring to the approach for the risk assessment of flavorings in the Joint FAO/WHO Expert Committee on Food Additives (JECFA) ${ }^{2}$ and European Food Safety Authority (EFSA) $)^{3}$.

FSCJ finalized the new guidelines for the risk assessment of flavoring substances based on the research report of the Yamazaki research group. From now on, the risk assessment of flavoring substances is conducted according to these guidelines.

The guidelines would be revised after reviewing their provisions, taking into account changes in international assessment guidelines and new scientific findings both within and outside Japan, if needed.

\section{Article 2: Definition}

\section{Flavoring substances}

"Flavoring substances" are substances used for the purpose of imparting aromas to food, which are categorized as "food additives." "Food additives" are defined in Article 4 paragraph (2) of the Food Sanitation Act (Law No. 233 of 1947) as substances which are used by being added, mixed, or infiltrated into food or by other methods in the process of producing food or for the purpose of processing or preserving food.

\section{Maximized Survey-Derived Intake (MSDI) method}

MSDI is a method to estimate intake of flavoring substances, calculated by dividing the annual production of the flavoring substance by $10 \%$ of the population and by the correction factor. The method is based on the assumption that $10 \%$ of the population in the region evenly consume the flavoring substance used in the region, a year. The method is also called as Per Capita intake Times Ten (PCTT) method.

\section{3. (Quantitative) Structure-Activity Relationship ((Q) SAR)}

(Quantitative) Structure-Activity Relationship ((Q) SAR) is defined as a (Quantitative) relationship between chemical structure or properties of a substance and its biological activity. It is used to predict effects or toxicological profiles of structurally related substances.

\section{Single Portion Exposure Technique (SPET) method}

The SPET method estimates intake of flavoring substances based on the assumption that a regular consumer eats one food-category of food containing a flavoring substance once a day. Food categories are defined in the Codex General Standard for Food Additives (GFSA). Any food categories where a flavoring substance is possibly used are specified. Intakes of the flavoring substance from each food category are calculated by multiplying the average added use level for the flavoring substance with standard portion sizes in each food category. Among the calculated intakes, the highest one is taken as the intake of the flavoring substance ${ }^{5}$.

\section{Human exposure threshold (threshold of concern)}

The Threshold of Toxicological Concern (TTC) is an approach to obtain the exposure levels of no concern to human health concerning trace substances contained in food, using the data on its related substances. It is based on the concept that the probability of adverse effects to human health caused by a substance is extremely low below a certain level of exposure, so that the threshold values can be established. TTC has been used for chemical substances of which intakes or exposure levels are very low, and for which it is difficult to obtain toxicological data from animal studies.

The exposure values estimated by the TTC approach are called as human exposure threshold (threshold of concern). JECFA uses these values for the safety evaluation of flavoring substances as exposure levels under which no safety concern is raised by the chemicals as long as it is used as a flavoring substance. Those values are established for each of three structural classes. In these guidelines, these values are used as human exposure thresholds of flavoring substances, referred to in the evaluation of the general toxicity ${ }^{2,6)}$. 


\section{Structural alert}

Structural alerts are functional groups or partial structures of chemical molecules related to a certain characteristics including toxicity. It is used to foresee whether a chemical substance causes adverse effects without conducting animal studies.

In these guidelines, the structural alerts are indicated in the list of structural alerts or alerting structures for genotoxicity (Appendix 3), which are used in the safety evaluation of flavoring substances by JECFA and other organizations. The structural alerts are referred to in the evaluation of the genotoxicity.

\section{Article 3: Purpose}

The purpose of the guidelines is to establish the guiding principle of risk assessment on flavoring substances and to define the scope of required information. Risk assessment is needed for the cases where the Minister of Health, Labour and Welfare (MHLW) intends to prescribe cases that are not injurious to human health as provided in Article 10 of the Food Sanitation Law, or where MHLW intends to establish specifications in accordance with the provisions of Article 11, paragraph (1) of the law, or where MHLW hears the Commission's opinions if they are recognized as necessary for formulating policies to ensure food safety in accordance with Article 24, paragraph (3) of the Food Safety Basic Act.

\section{Article 4: Approach for the Risk Assessment of Flavoring Substances}

\section{Procedure of the risk assessment}

First, the genotoxicity of the target flavoring substance in the assessment (hereinafter referred to as "the target substance") is verified. If the target substance is of no concern on genotoxicity, the general toxicity is evaluated based on the intake estimation.

\section{Genotoxicity}

The genotoxicity of the target substance may be evaluated, through referring to the results of genotoxicity studies on the structurally and metabolically related substance, even in the cases where relevant experimental results on the target substance are not available. The related substance groups listed in Appendix 2 are used to judge whether a substance is an appropriate related substance. The related substance groups would be revised, taking into account new scientific findings, if needed.

Information on the prediction of Ames test results by (Q) SAR on the target substance and its related substances are used as additional auxiliary materials for the time being. Such auxiliary status of the materials would be revised, if needed, after the principle of (Q) SAR approach for the risk assessment is established in FSCJ.

Information on the existence of the structural alert adopted by JECFA etc. (Appendix 3) in the target substance and its related substances are used as additional auxiliary materials for the time being. The structural alert would be revised, taking into account new scientific findings, if needed.

\section{General Toxicity}

The general toxicity of the target substance is evaluated through the TTC approach. The target substance is classified into one of the three structural classes. The estimated intake of the target substance is compared to the human exposure threshold of the structural class. If the estimated intake of the target substance is below the human exposure threshold, it is judged that the substance would not be expected to be of safety concern ${ }^{2}$.

If the estimated intake of the target substance is beyond the human exposure threshold, it is verified whether an adequate margin exists, comparing the estimated intake with the NOAEL obtained from repeated-dose toxicity studies and other studies.

The results from the predicting software of human metabolites are used as additional auxiliary materials.

\section{Intake Estimation}

The amount of intake is estimated through the MSDI method, for the time being.

\section{Other}

The results of assessment by JECFA, EFSA, FDA and other overseas organizations are reviewed, if needed. 


\section{Chapter 2: Approach for the Assessment and Required Information}

\section{Article 1: Outline of the Target Substance}

The required information is shown below. Contents of each item follow the "Guideline for Assessment of the Effect of Food on Human Health Regarding Food Additives" (May 27, 2010)

(1) Name and usage

(2) Physicochemical properties

Chemical name (generic names in Japanese and English, CAS number), molecular formula, molecular weight, structural formula, manufacturing method, description, stability, draft specifications, etc.

(3) Usage in other countries

(4) Risk assessments by international organizations and other organizations

(5) Origin or history of discovery

(6) Other (information useful for the risk assessment)

\section{Article 2: Genotoxicity}

\section{Procedure of the evaluation}

Fig. 1 summarizes the procedure of the evaluation of the genotoxcity.

\section{Explanation of each step in the evaluation of the genotoxicity}

Each step in the evaluation of the genotoxicity is conducted as follows.

First, it is verified whether it is possible to conduct the evaluation based on the results from genotoxicity studies of the target substance.

- If YES, proceed to Step 2.

- If NO, the genotoxicity of the target substance may be evaluated based on the results from genotoxicity studies on the structurally and metabolically related substances.

It is judged whether there are any appropriate related substances for the evaluation,

If YES, proceed to Step 1.

If NO, proceed to Step 2.

Whether a substance is an appropriate related substance is judged as follows. First, the target substance is assigned to one of the related substance groups shown in Appendix 2 on the basis of structural and metabolic similarity. Then it is verified whether there are sufficient experimental data concerning genotoxicity on the substances belonging to the related substance group.

The groups shown in Appendix 2 are defined with reference to the classification of Flavoring Group Evaluation (FGE) by EFSA. It would be revised, taking into account new scientific findings, if needed.

In the case where the target substance is assigned to the related substance group in which any of the substance has already been evaluated, the evaluation on the substance may be applied to the target substance, even if no genotoxicity data on the target substance is available.

The target substance and the related substance, which cannot be assigned to one of the groups shown in Appendix 2 , are evaluated individually.

(1) Step 1.

At Step 1, it is verified whether there are any concerns for genotoxicity based on the results of genotoxicity studies on the related substance. At Step 1, it is judged based on at least the results from bacterial reverse mutation tests (hereinafter referred to as "Ames test") and chromosome aberration tests using mammalian cultured cells. The chromosome aberration tests using mammalian cultured cells can be replaced with a mouse lymphoma TK assay or in vitro / in vivo micronucleus tests.

If it is judged there is no concern, the target substance is judged to be of no concern for genotoxicity. 


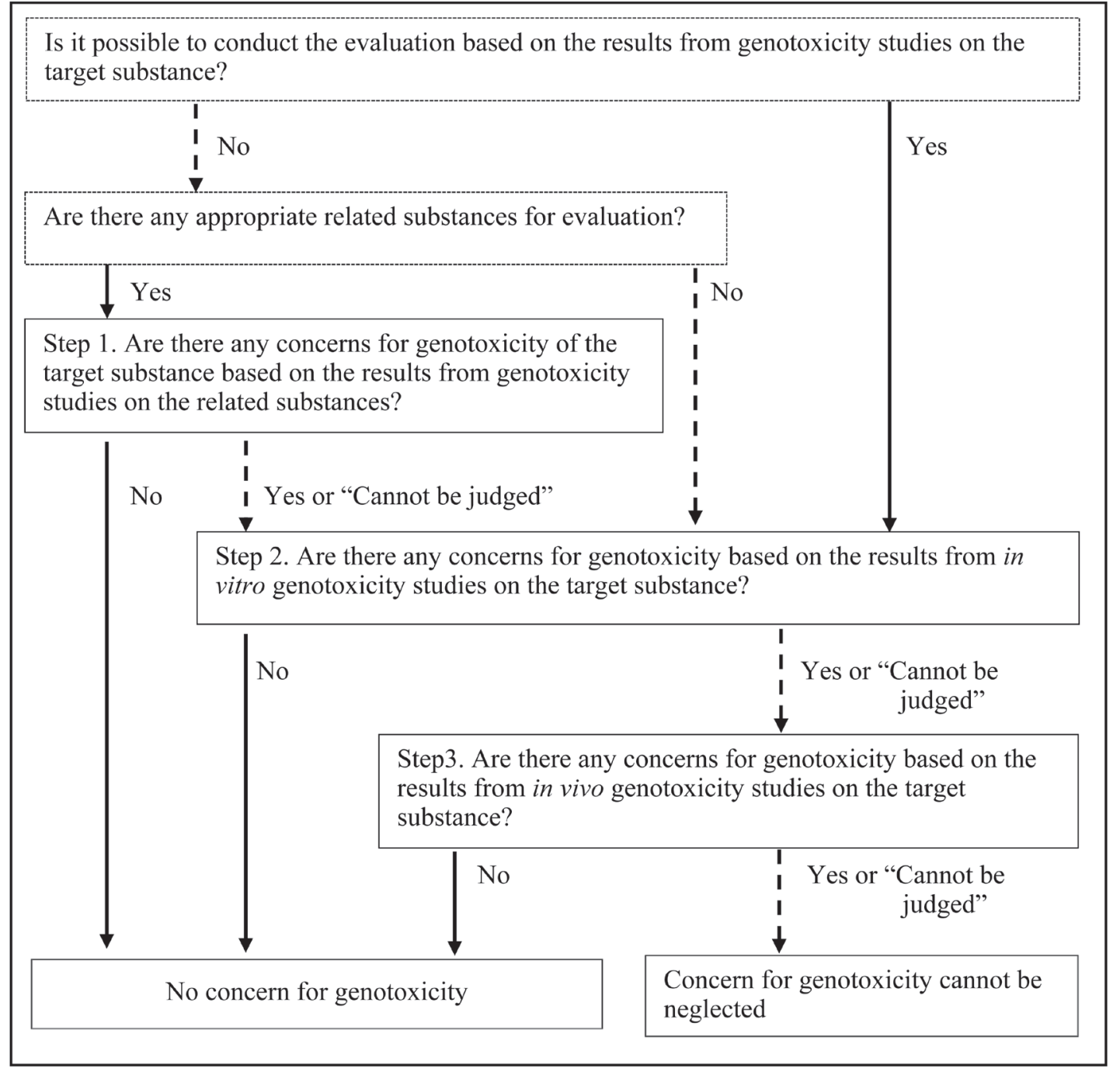

Fig. 1. Procedure of the evaluation of the genotoxicity

If it is judged there is concern, or if it cannot be judged from the existing data, proceed to Step 2 .

(2) Step 2.

At Step 2, it is verified whether there are any concerns for genotoxicity based on the results from in vitro genotoxicity studies on the target substance. At Step 2, as at Step 1, it is judged based on at least Ames tests and chromosome aberration tests using mammalian cultured cells. The chromosome aberration tests using mammalian cultured cells can be replaced with a mouse lymphoma TK assay or in vitro / in vivo micronucleus tests.

If it is judged there is no concern, proceed to the evaluation of the general toxicity.

If it is judged there is concern, or if it cannot be judged from the existing data, proceed to Step 3 .

(3) Step 3.

At Step 3, it is verified whether there are any concerns for genotoxicity based on the results from in vivo genotoxicity studies on the target substance, considering the results from the studies used at Step 2 together.

If it is judged there is no concern, proceed to the evaluation of the general toxicity.

If it is judged there is concern, or if it cannot be judged from the existing data, concerns for genotoxicity cannot be neglected on the target substance. Thus the evaluation of the general toxicity is not followed. 


\section{Information required for evaluation}

The applicant is required to provide the following information. In principle, the studies should comply with the internationally recognized test guidelines, such as OECD Test Guidelines.

Documents containing the results of genotoxicity studies on the target substance, or the scientific rationales. In the case where such documents cannot be submitted, documents containing the results of genotoxicity studies on the related substances, or the scientific rationales. In the latter case, the applicant is also required to submit the basis to consider that it is appropriate to use the experimental results on the related substance for the evaluation of the target substance.

The applicant is encouraged to provide information on the existence of structural alerts used by JECFA and other organizations (Appendix 3) on the target substance and the related substances.

The applicant should provide the following information, if available.

The prediction of Ames test results on the target substance and related substances through (Q) SAR approach.

Other safety relevant information useful for the evaluation of the genotoxicity.

\section{Article 3: General Toxicity}

\section{Procedure of the evaluation}

The general toxicity of the target substance is evaluated through the TTC approach. The target substance is classified into one of the three structural classes. The estimated intake of the target substance is compared to the human exposure threshold of the structural class. The judgment at Step B5 of the safety evaluation sequence of JECFA ${ }^{2}$, which is based on the parameter of $1.5 \mu \mathrm{g} /$ person/day, is not used in these guidelines, as in the former guidelines.

The procedure of the evaluation of the general toxicity is summarized in Fig. 2.

\section{Explanation of each step in the evaluation of the general toxicity}

Each step in the evaluation of the general toxicity is conducted as follows.

\section{(1) Step 1.}

At Step 1, the target substance is classified into one of Structural Class-I, -II or -III, based on its chemical structure and estimated metabolic pathways, among other factors. The questions shown in Appendix 4 (see Appendix 4 and Appendix 5) are used for the criteria for the classification.

The structural class classification approach in these guidelines is based on the structure class approach by Cramer ${ }^{8)}$. FSCJ, however, considered it inappropriate to apply Cramer Question 33 for the classification of Class-I. Thus, Question 33 is not included in these guidelines, as in the former guidelines ${ }^{1)}$.

\section{(2) Step 2.}

At Step 2, it is verified whether the target substance can be predicted to undergo metabolism to innocuous products. "Innocuous products" are defined as metabolites that are known or readily predicted to be harmless to humans at the estimated intakes of the target substance as a flavoring substance.

The metabolites would be evaluated based on the relevant documents containing experimental appropriate results or scientific rationales. In the cases where the results from animal studies are used, it is considered whether the results can be extrapolated to humans.

Metabolic pathways to be considered include hydrolysis of esters, oxidation of alcohols and aldehydes, reduction of ketones, reduction of double bonds, oxidation of side-chains, oxidation of alicyclic compounds, conjugation of alcohols, and glutathione conjugations.

If it can be predicted to undergo metabolism to innocuous products, proceed to Step A3.

If it cannot be predicted to undergo metabolism to innocuous products, proceed to Step B3.

(3) Step A3 and Step B3.

At Step A3 and Step B3, it is verified whether the conditions of use result in an intake greater than the human exposure threshold for the structural class. 


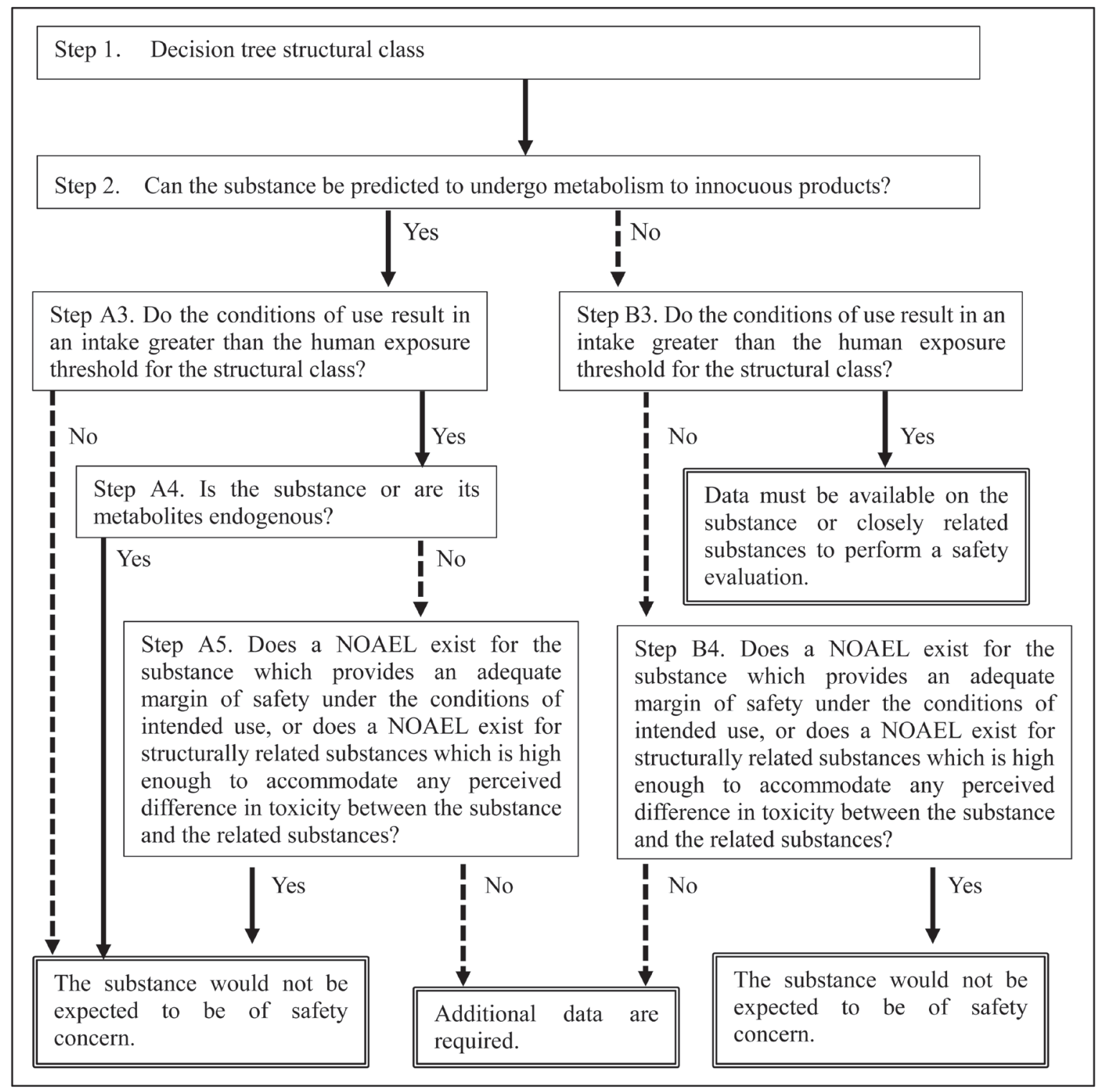

Fig. 2. Procedure of the evaluation of the general toxicity

The estimated intake of the target substance is compared with the human exposure threshold specified in each

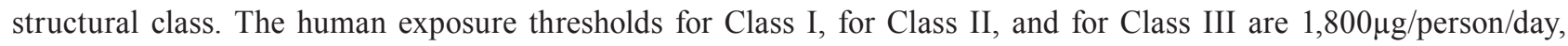
$540 \mu \mathrm{g} / \mathrm{person} / \mathrm{day}$, and $90 \mu \mathrm{g} / \mathrm{person} / \mathrm{day}$, respectively ${ }^{2,6)}$. (Appendix 6)

At Step A3, if the estimated intake of the target substance is below the human exposure threshold of the structural class, it is judged that the target substance would not be expected to be of safety concern. If the estimated intake is beyond the human exposure threshold, proceed to Step A4.

At Step B3, if the estimated intake of the target substance is below the human exposure threshold of the structural class, proceed to Step B4. In the case where the estimated intake is beyond the human exposure threshold of the relevant structural class, it is judged that data must be available on the substance or closely related substances sufficient to perform a safety evaluation.

\section{(4) Step A4.}

At Step A4, it is verified whether the target substance or its metabolites is/are endogenous substances.

Endogenous substances are mostly alcohols, aldehydes, ketones, acids or their corresponding esters, acetals as well as ketals. These are rapidly metabolized to harmless end products through well-known pathways, being catalyzed by enzymes in cells with high specificity and high catalytic efficiency. These include intermediary metabolites normally 
present in human tissues and fluids, whether free or conjugated. Hormones and other substances with biochemical or physiological regulatory functions are not included.

If YES, it is judged that the target substance would not be expected to be of safety concern.

If NO, proceed to Step A5.

\section{(5) Step A5 and Step B4}

It is verified whether a NOAEL exists for the substance which provides an adequate margin of safety under the conditions of intended use, or whether a NOAEL exists for structurally related substances which is high enough to accommodate any perceived difference in toxicity between the substance and the related substances.

If YES, it is judged that the target substance would not be expected to be of safety concern.

If $\mathrm{NO}$, it is judged that additional data are required.

The risk assessment of flavoring substances in Japan has been conducted mainly using the results of 90-day toxicity study as the repeated-dose toxicity study. It is appropriate to use studies with 90 or more days of administration period for NOAEL specification. If the administration period of the study is less than 90 days, the other scientific data are considered together.

It is appropriate to apply an apriori safety margin of 1,000 for NOAELs of 90-day repeated-dose toxicity studies, considering the former guidelines as well as the current approach in JECFA.

NOAELs of the related substances referred to in the evaluation of general toxicity may be used instead of a NOAEL of the target substance itself. In such cases, whether the substance is an appropriate related substance is verified.

The higher similarity of the related substance to the target substance is required in the evaluation of the general toxicity than in the evaluation of the genotoxicity. Even if a flavoring substance belongs to the same related substance group as the target substance belongs to (Appendix 2), the favoring substance cannot always be an appropriate related substance. Not only the prediction of metabolites, but the toxicological relevance is an important point in considering whether it is an appropriate related substance for the NOAEL. For example, in a case where the target substance and the related substance are considered to undergo metabolism to the same metabolite, an appropriate related substance needs to be identified through the consideration of further points, including whether the metabolite is a causative substance for toxicity of the target substance, or whether the metabolite is a detoxified substance. In addition, since the NOAEL is a quantitative value that needs to consider difference in species, the quantitative analysis on kinetics, such as absorption and distribution of the target substance and the related substance, should be considered in the judgment.

In the case where there is no appropriate related substance, the NOAEL of the target substance itself is used.

\section{Information required for evaluation}

The applicant is required to provide the following information. In principle, the studies should comply with the internationally recognized test guidelines, such as OECD Test Guidelines.

Information on the structural classification of the target substance

Documents containing the results of metabolic studies on the target substance, or the scientific rationales.

Information on the estimated intake of the target substance. The estimated intake is explained in "Article 4: Estimation of daily intake."

At Step A5 or at Step B4, information on the specification of NOAELs for the target substance. In the case where such information cannot be submitted, information on the specification of NOAELs for the related substances. In the latter case, the applicant is also required to submit the basis to consider that it is appropriate to use the experimental results on the related substance for the evaluation of the target substance.

The applicant should provide the following information, if available.

Information on kinetics of the target substance

The results from the predicting software of human metabolite

Other safety relevant information useful for the evaluation of the general toxicity 


\section{Article 4: Estimation of Daily Intake}

\section{Approach for assessment}

The estimation of daily intake of the target substance "under the conditions of use" referred to at Step A3 and at Step B3, as well as "under the conditions of intended use" referred to at Step A5 and at Step B4 are calculated from intakes due to the addition of flavoring substances to foods, not from those naturally present in foods.

In the former guidelines, the Maximized Survey-Derived Intake (MSDI) method (PCTT method) was used to estimate the daily intakes of flavoring substances in Japan. The method assumes that the amount of flavoring substances used in a year is consumed evenly by $10 \%$ of the population. The daily intakes of flavoring substances are calculated through dividing the annual production of flavoring substances by $10 \%$ of the population (assumed consuming population) and by the correction factor (survey response rate) (JECFA adopts $80 \%(0.8)$ at the maximum) $)^{9}$. The following formula is used for the calculation of the estimated intake based on the definition of the MSDI method mentioned in "Article 2: Definition."

$$
\text { Estimated intake }(\mu \mathrm{g} / \text { person } / \text { day })=\frac{\text { Amount ofannual use }(\mathrm{kg}) \times 10^{9}(\mu \mathrm{g} / \mathrm{kg})}{\text { Consuming population } \times \text { Survey response rate } \times 365(\text { day })}
$$

JECFA also uses the single portion exposure technique (SPET) method ${ }^{5)}$, as well as the MSDI method. It is expected to also use the SPET method in Japan to be consistent with the international approach. The SPET method used by JECFA is, however, based on the dietary habits in European countries and the US. Thus, at present, the estimation of the intake of flavoring substances in Japan is conducted by the MSDI method.

FSCJ applies the same survey response rate as JECFA, as in the former guidelines. A more appropriate method for intake estimation needs to be developed that reflects the dietary habits in Japan.

\section{Information required for assessment}

The applicant is required to provide information on the amount of annual use and the estimated intake calculated from the data on the amount of annual use using the formula of the MSDI method. In the case where the use of the target substance is not approved in Japan, estimated intakes calculated from the data on the amount of annual use in foreign countries (e.g. European countries or the US) are acceptable. 


\section{Appendix 1: Abbreviations}

\begin{tabular}{ll}
\hline \multicolumn{1}{c}{ Abbreviation } & \\
\hline EFSA & European Food Safety Authority \\
EU & European Union \\
FDS & Food Additives Series \\
FGE & Flavoring Group Evaluation \\
GSFA & General Standard for Food Additives \\
JECFA & Joint FAO/WHO Expert Committee on Food Additives \\
MSDI & Maximized Survey-Derived Intake \\
OECD & Organization for Economic Co-operation and Development \\
PCTT & Per Capita intake Times Ten \\
(Q) SAR & (Quantitative) Structure-Activity Relationship \\
SPET & Single Portion Exposure Technique \\
TTC & Threshold of Toxicological Concern \\
\hline
\end{tabular}




\section{Appendix 2: Related Substance Groups}

\section{Related Substance Group}

Referred FGE of EFSA

Branched-chain aliphatic saturated aldehydes, carboxylic acids and related esters of primary alcohols and FGE.01Rev2 ${ }^{10)}$ branched-chain carboxylic acids

Branched- and straight-chain aliphatic saturated primary alcohols and related esters of primary alcohols FGE.02Rev1 ${ }^{11)}$ and straight-chain carboxylic acids and one straight-chain aldehyde

Acetals of branched- and straight-chain aliphatic saturated primary alcohols and branched- and straight- FGE.03Rev2 ${ }^{12}$ ) chain saturated or unsaturated aldehydes, an ester of a hemiacetal and an orthoester of formic acid

\begin{tabular}{ll}
\hline 2-Ethylhexyl derivatives & FGE.04 ${ }^{13)}$ \\
\hline $\begin{array}{l}\text { Branched- and straight-chain unsaturated carboxylic acids and esters of these with aliphatic saturated } \\
\text { alcohols }\end{array}$ & FGE.05Rev2 ${ }^{14)}$ \\
\hline $\begin{array}{l}\text { Straight- and branched-chain aliphatic unsaturated primary alcohols, aldehydes, carboxylic acids and } \\
\text { esters }\end{array}$ & FGE.06Rev4 $\left.{ }^{15}\right)$ \\
\hline
\end{tabular}

Saturated and unsaturated aliphatic secondary alcohols, ketones and esters of secondary alcohols and $\quad$ FGE.07Rev4 ${ }^{16)}$ saturated linear or branched-chain carboxylic acids

Aliphatic and alicyclic mono-, di-, tri-, and polysulphides with or without additional oxygenated func- $\quad$ FGE.08Rev5 ${ }^{17)}$ tional groups

Secondary alicyclic saturated and unsaturated alcohols, ketones and esters containing secondary alicyclic FGE.09Rev5 ${ }^{18)}$ alcohols and an ester of a phenol derivative

Aliphatic primary and secondary saturated and unsaturated alcohols, aldehydes, acetals, carboxylic acids FGE.10Rev3 ${ }^{19}$ and esters containing an additional oxygenated functional group and lactones

\begin{tabular}{|c|c|}
\hline Aliphatic dialcohols, diketones, and hydroxyketones & FGE.11Rev3 $3^{20)}$ \\
\hline Primary saturated or unsaturated alicyclic alcohol, aldehyde, acid, and esters & FGE.12Rev $5^{21)}$ \\
\hline Furfuryl and furan derivatives with and without additional side-chain substituents and heteroatoms & FGE.13Rev222) \\
\hline Phenethyl alcohol, aldehyde, acetals, carboxylic acid and related esters & FGE.14Rev2 23$)$ \\
\hline Aryl-substituted saturated and unsaturated primary alcohol/aldehyde/acid/ester derivatives & FGE.15Rev2 ${ }^{24)}$ \\
\hline Aromatic ketones & FGE.16Rev2 25$)$ \\
\hline Pyrazine derivatives & FGE.17Rev3 $3^{26)}$ \\
\hline $\begin{array}{l}\text { Aliphatic, alicyclic and aromatic saturated and unsaturated tertiary alcohols, aromatic tertiary alcohols } \\
\text { and their esters }\end{array}$ & FGE.18Rev3 $3^{27)}$ \\
\hline Benzyl alcohols, benzaldehydes, a related acetal, benzoic acids, and related esters & FGE.20Rev4 ${ }^{28)}$ \\
\hline Thiazoles, thiophenes, thiazoline and thienyl derivatives & FGE.21Rev $5^{29)}$ \\
\hline Ring-substituted phenolic substances & FGE.22Rev1 ${ }^{30)}$ \\
\hline Aliphatic, alicyclic and aromatic ethers including anisole derivatives & FGE.23Rev4 $3^{31)}$ \\
\hline Pyridine, pyrrole, indole and quinoline derivatives & FGE.24Rev2 ${ }^{32)}$ \\
\hline Aliphatic hydrocarbons & FGE.25Rev3 ${ }^{33)}$ \\
\hline Amino acids & FGE. 26 $6^{34)}$ \\
\hline One aromatic lactone & FGE. 27 35$)$ \\
\hline Vinylbenzene & FGE.2936) \\
\hline $\begin{array}{l}\text { 4-Prop-1-enylphenol and 2-methoxy-4-(prop-1-enyl)phenyl 3- } \\
\text { methylbutyrate }\end{array}$ & FGE.30Rev1 ${ }^{37)}$ \\
\hline
\end{tabular}


Appendix 2. Related Substance Groups (continued)

\begin{tabular}{|c|c|}
\hline Related Substance Group & Referred FGE of EFSA \\
\hline One Epoxide & FGE.31 38$)$ \\
\hline Flavonoids (Flavanones and dihydrochalcones) & FGE.32 $2^{39)}$ \\
\hline Six Tetrahydrofuran Derivatives & FGE. $33^{40)}$ \\
\hline One tetrahydroquinoline derivative & FGE.34 ${ }^{41)}$ \\
\hline Three quinine salts & FGE. $35^{42)}$ \\
\hline Two triterpene glycosides & FGE.36 $6^{43)}$ \\
\hline 3-Butenyl isothiocyanate & FGE38 ${ }^{44)}$ \\
\hline An aromatic derivative of 2-hydroxy-propionamide & FGE.40 45$)$ \\
\hline Ion containing organic substances & FGE.4246) \\
\hline Thujyl alcohol & FGE.43 ${ }^{47)}$ \\
\hline cis-2-Heptyl-cyclopropanecarboxylic Acid & FGE.44 ${ }^{48)}$ \\
\hline One tertiary amine & FGE.45 49$)$ \\
\hline Ammonia and three ammonium salts & FGE.46Rev1 ${ }^{50)}$ \\
\hline Bi- and tricyclic secondary alcohols, ketones and related esters & FGE.47Rev1 ${ }^{51)}$ \\
\hline Aminoacetophenone & FGE.48 ${ }^{52)}$ \\
\hline Xanthin alkaloids & FGE.4953) \\
\hline $\begin{array}{l}\text { Pyrazine derivatives evaluated by JECFA ( } 57 \text { th meeting) structurally related to pyrazine derivatives } \\
\text { evaluated in FGE.17Rev2 }\end{array}$ & FGE.50Rev1 ${ }^{54)}$ \\
\hline
\end{tabular}

Alicyclic ketones and secondary alcohols and related esters evaluated by the JECFA (59th meeting) struc- FGE.51Rev1 ${ }^{55)}$ turally related to alicyclic ketones secondary alcohols and related esters in FGE.09Rev3

Hydroxy- and alkoxy-substituted benzyl derivatives evaluated by JECFA (57th meeting) structurally FGE.52 $2^{56)}$ related to benzyl alcohols, benzaldehydes, a related acetal, benzoic acids, and related esters evaluated in FGE.20

Phenethyl alcohol, aldehyde, acid and related acetals and esters evaluated by JECFA (59th meeting) and structurally related to phenethyl alcohol, aldehyde, esters and related phenylacetic acid esters evaluated in FGE.14Revl and one phenoxyethyl ester evaluated in FGE.23Rev1

Benzyl derivatives evaluated by JECFA (57th meeting) structurally related to benzyl alcohols, benzalde- FGE.54Rev1 ${ }^{58)}$ hydes, a related acetal, benzoic acids and related esters evaluated in FGE.20Rev1

Phenyl-substituted aliphatic alcohols and related aldehydes and esters evaluated by JECFA (63rd meeting) FGE.555) structurally related to phenethyl alcohol, aldehyde, esters and related phenylacetic acid esters evaluated in FGE.14 and aryl-substituted saturated and unsaturated primary alcohol/aldehyde/acid/ester derivatives evaluated in FGE.15

Monocyclic and alcohols, ketones and related esters evaluated by JECFA (63rd meeting) structurally related to secondary alicyclic saturated and unsaturated alcohols, ketones and esters containing secondary alicyclic alcohols and an ester of a phenol carboxylic acid evaluated in FGE.09Rev1

Two structurally related pulegone metabolites and one ester thereof evaluated by JECFA (55th meeting)

FGE. $57^{61}$

Phenol derivatives evaluated by JECFA (55th meeting) structurally related to ring substituted phenolic substances evaluated in FGE.22

FGE.53Rev1 ${ }^{57)}$

Aliphatic and aromatic ethers evaluated by JECFA (61st meeting and 63rd meeting) structurally related to FGE.59Rev1 ${ }^{63)}$ aliphatic, alicyclic and aromatic ethers including anisole derivatives evaluated in FGE.23 Rev2

Eugenol and related hydroxyallylbenzene derivatives evaluated by JECFA (65th meeting) structurally related to ring-substituted phenolic substances evaluated in FGE.22

FGE. $56^{60)}$

FGE. 58 $8^{62)}$ 
Appendix 2. Related Substance Groups (continued)

\begin{tabular}{lc}
\hline \multicolumn{1}{c}{ Related Substance Group } & Referred FGE of EFSA \\
\hline $\begin{array}{l}\text { Aliphatic acetals evaluated by JECFA (57th meeting) structurally related to acetals of branched- and } \\
\text { straight-chain aliphatic saturated primary alcohols and branched- and straight-chain saturated aldehydes } \\
\text { and one orthoester of formic acid evaluated in FGE.03Rev1 }\end{array}$ & FGE.61Rev165) \\
\hline
\end{tabular}

Linear and branched-chain aliphatic unsaturated, unconjugated alcohols, aldehydes, acids, and related es- FGE.62Rev1 ${ }^{66)}$ ters evaluated by JECFA (61st and 68th meeting) structurally related to branched- and straight-chain unsaturated carboxylic acids and esters of these with aliphatic saturated alcohols evaluated in FGE.05Rev2 and to straight- and branched-chain aliphatic unsaturated primary alcohols, aldehydes, carboxylic acids, and esters evaluated in FGE.06Rev1

Aliphatic secondary alcohols, ketones and related esters evaluated by JECFA (59th and 69th meetings) structurally related to saturated and unsaturated aliphatic secondary alcohols, ketones and esters of secondary alcohols and saturated linear or branched-chain carboxylic acids evaluated in FGE.07Rev4

Aliphatic acyclic diols, triols, and related substances evaluated by JECFA (57th meeting) structurally related to aliphatic primary and secondary saturated and unsaturated alcohols, aldehydes, acetals, carboxylic acids and esters containing an additional oxygenated functional group and lactones from chemical groups 9, 13 and 30 evaluated in FGE.10Rev1

Sulfur-substituted furan derivatives used as flavouring agents evaluated by JECFA (59th meeting) structurally related to a subgroup of substances within the group of 'Furfuryl and furan derivatives with and without additional side-chain substituents and heteroatoms from chemical group 14' evaluated in FGE.13Rev2

\begin{tabular}{ll}
\hline Furfuryl Alcohol and Related Flavouring Substances Evaluated by JECFA (55th meeting) & FGE.66Rev1 ${ }^{70)}$ \\
\hline Furan-substituted compounds evaluated by JECFA at the 55th, 65th and 69th meetings & FGE.67Rev2 ${ }^{71)}$ \\
\hline $\begin{array}{l}\text { Cinnamyl alcohol and related flavouring agents evaluated by JECFA (55th meeting) structurally related } \\
\text { to aryl-substituted saturated and unsaturated primary alcohol/aldehyde/acid/ester derivatives evaluated in }\end{array}$ & FGE.68 \\
FGE.15Rev1 & \\
\hline
\end{tabular}

Aromatic substituted secondary alcohols, ketones and related esters evaluated by JECFA (57th meeting) FGE.6973) structurally related to aromatic ketones from chemical group 21 evaluated in FGE.16

Aliphatic, alicyclic, linear, alpha,beta-unsaturated, di- and trienals and related alcohols, acids and esters $\quad$ FGE.70 ${ }^{74)}$ evaluated by JECFA (61st meeting)

Aliphatic, linear, alpha,beta-unsaturated carboxylic acids and related esters evaluated by JECFA (63rd meeting) structurally related to esters of branched- and straight-chain unsaturated carboxylic acids. Esters of these and straight-chain aliphatic saturated alcohols evaluated by in FGE.05Rev2

Aliphatic, branched-chain saturated and unsaturated alcohols, aldehydes, acids, and related esters evaluated by the JECFA (61st meeting) structurally related to branched- and straight-chain unsaturated carboxylic acids, esters of these and straight-chain aliphatic saturated alcohols evaluated in FGE.05Rev2
Alicyclic alcohols, aldehydes, acids and related esters evaluated by JECFA (59th and 63rd meeting) structurally related to primary saturated or unsaturated alicyclic alcohols, aldehydes, acids and esters evaluated in FGE.12Rev4
Simple Aliphatic Sulphides and Thiols evaluated by the JECFA (53rd and 61st meeting) Structurally relat- FGE.74Rev3 ${ }^{78)}$ ed to Aliphatic and Alicyclic Mono-, Di-, Tri-, and Polysulphides with or without Additional Oxygenated Functional Groups from Chemical Group 20 evaluated in FGE.08Rev5

FGE.7175)

\begin{tabular}{ll}
\hline $\begin{array}{l}\text { Tetrahydrofuran derivatives and a furanone derivative evaluated by JECFA (63rd meeting) structurally } \\
\text { related to tetrahydrofuran derivatives evaluated in FGE.33 }\end{array}$ & FGE.7579) \\
\hline $\begin{array}{l}\text { Sulphur-containing heterocyclic compounds evaluated by JECFA (59th meeting) structurally related to } \\
\text { thiazoles, thiophene, thiazoline and thienyl derivatives from chemical group } 29 \text { and miscellaneous sub- }\end{array}$ & FGE.76Rev1 ${ }^{80)}$ \\
stances from chemical group 30 evaluated in FGE.21Rev3 & \\
\hline
\end{tabular}

Pyridine, Pyrrole and Quinoline Derivatives evaluated by JECFA (63rd meeting) structurally related to FGE.7781) Pyridine, Pyrrole, Indole and Quinoline Derivatives evaluated in FGE.24Rev2

Aliphatic and alicyclic and aromatic hydrocarbons evaluated by JECFA (63rd meeting) structurally related to aliphatic hydrocarbons evaluated in FGE.25Rev3 
Appendix 2. Related Substance Groups (continued)

\begin{tabular}{lc}
\hline \multicolumn{1}{c}{ Related Substance Group } & Referred FGE of EFSA \\
\hline $\begin{array}{l}\text { Amino acids and related substances evaluated by JECFA (63rd meeting) structurally related to amino } \\
\text { acids from chemical group 34 evaluated in FGE.26Rev1 }\end{array}$ & FGE.79 \\
\hline $\begin{array}{l}\text { Alicyclic, alicyclic-fused and aromatic-fused ring lactones evaluated by JECFA (61st meeting) structur- } \\
\text { ally related to an aromatic lactone evaluated in FGE.27 }\end{array}$ & FGE.80Rev1 $^{84)}$ \\
\hline
\end{tabular}

Hydroxypropenylbenzenes evaluated by JECFA (61st meeting) structurally related to 2-methoxy-4-(prop- FGE.81 ${ }^{85}$ ) 1-enyl)phenyl 3-methylbutyrate from chemical group 17 evaluated in FGE.30

\begin{tabular}{|c|c|}
\hline Epoxides evaluated by the JECFA (65th meeting) & FGE.82Rev1 $1^{86)}$ \\
\hline Ethyl maltol and two 6-keto-1,4-dioxane derivatives substances evaluated by JECFA ( 65 th meeting) & FGE.83Rev1 ${ }^{87)}$ \\
\hline Anthranilate derivatives evaluated by JECFA ( 65 th meeting) & FGE.84 ${ }^{88)}$ \\
\hline Miscellaneous nitrogen-containing substances evaluated by JECFA (65th meeting) & FGE.85 89$)$ \\
\hline Aliphatic and arylalkyl amines and amides evaluated by JECFA (65th meeting) & FGE.86Rev2 $2^{90)}$ \\
\hline $\begin{array}{l}\text { Bicyclic secondary alcohols, ketones and related esters evaluated by JECFA (63rd meeting) structurally } \\
\text { related to bicyclic secondary alcohols, ketones and related esters evaluated in FGE.47Rev1 }\end{array}$ & FGE.87Rev291) \\
\hline Phenol and Phenol Derivatives evaluated by JECFA ( 55 th meeting) & FGE. $88^{92)}$ \\
\hline $\begin{array}{l}\text { Phenyl-substituted aliphatic tertiary alcohols and related aldehydes and esters evaluated by JECFA (63rd } \\
\text { and 68th meetings) structurally related to aliphatic, alicyclic and aromatic saturated and unsaturated } \\
\text { tertiary alcohols, aromatic tertiary alcohols and their esters evaluated in FGE.18Revl }\end{array}$ & FGE.8993) \\
\hline
\end{tabular}

Aliphatic, acyclic and alicyclic terpenoid tertiary alcohols and structurally related substances evaluated

FGE.9094) by JECFA (68th meeting) structurally related to aliphatic, alicyclic and aromatic saturated and unsaturated tertiary alcohols, aromatic tertiary alcohols and their esters evaluated in FGE.18Rev1

Simple aliphatic and aromatic sulphides and thiols evaluated by the JECFA (53rd and 68th meetings)

FGE.91Rev2 ${ }^{95)}$ structurally related to aliphatic and alicyclic mono-, di-, tri-, and polysulphides with or without additional oxygenated functional groups evaluated in FGE.08Rev5

Aliphatic acyclic diols, triols, and related substances evaluated by JECFA (68th meeting) structurally related to aliphatic primary and secondary saturated and unsaturated alcohols, aldehydes, acetals, carboxylic acids and esters containing an additional oxygenated functional group and lactones evaluated in FGE.10Rev1

Sulphur containing heterocyclic compounds evaluated by JECFA (68th meeting) structurally related to thiazoles, thiophene, thiazoline and thienyl derivatives evaluated in FGE.21Rev3

Aliphatic amines and amides evaluated in an addendum to the group of aliphatic and aromatic amines and amides evaluated by the JECFA (68th meeting)

Aliphatic, linear or branched-chain saturated and unsaturated alcohols, aldehydes, acids and related esters evaluated by JECFA (69th meeting) structurally related to esters of branched- and straight-chain aliphatic saturated primary alcohols and of one secondary alcohol, and branched- and straight-chain unsaturated carboxylic acids evaluated in FGE.05Rev1

88 flavouring substances considered for which EU production volumes / anticipated production volumes have been submitted on request by DG SANCO Addendum to FGE. 51, 52, 53, 54, 56, 58, 61, 62, 63, 64, $68,69,70,71,73,76,77,79,80,83,84,85$ and 87 


\section{Appendix 3: Structural Alerts}

1. The following structural alerts are listed in WHO Food Additives Series 40 Annex 5 Table 4. A list of functional groups identified by Ashby \& Tennant $(1988,1991)$ and Tennant et al. (1990) as structural alerts for DNA reactivity.
a) alkyl esters of phosphonic or sulfonic acids
b) aromatic nitro-groups
c) aromatic azo-groups (reduction to amine)
d) aromatic ring $\mathrm{N}$-oxides
e) aromatic mono- and di-alkyl amino groups
f) alkyl hydrazines
g) alkyl aldehydes
h) N-methylol derivatives
i) monohaloalkanes
j) Nitrogen and Sulfur mustards, beta-haloethyl-
k) N-chloramines
1) propiolactones and propiosulfones
m) aromatic and aliphatic aziridinyl derivatives
n) aromatic and aliphatic substituted primary alkyl halides
o) urethane derivatives (carbamates)
p) alkyl N-nitrosamines
q) aromatic amines and N-hydroxy derivatives
r) aliphatic epoxides and aromatic oxides
s) center of Michael reactivity
t) halogenated methanes
u) aliphatic nitro groups

2. Others

v) $\alpha, \beta$-unsaturated carbonyl compounds ${ }^{103)}$

w) furan derivatives ${ }^{104)}$ 


\section{Appendix 4: Questions for the Structural Class Classification ${ }^{1,8,105)}$}

\begin{tabular}{|c|c|c|c|}
\hline & \multirow{2}{*}{ Question } & \multicolumn{2}{|c|}{ Reply to the question } \\
\hline & & "No" & "Yes" \\
\hline 1 & Is the substance a normal constituent of the body, or an optical isomer of such? & Proceed to Q-2 & Class 1 \\
\hline 2 & $\begin{array}{l}\text { Does the substance contain any of the following functional groups? } \\
\text { - Aliphatic secondary amine or a salt thereof } \\
\text { - Cyano, } N \text {-nitroso, diazo, triazeno group } \\
\text { - Quaternary nitrogen, except in any of the following forms: }>\mathrm{C}=\mathrm{N}^{+} \mathrm{R}_{2} \text {, } \\
>\mathrm{C}=\mathrm{N}^{+} \mathrm{H}_{2} \text { or the hydrochloride or sulphate salt of a primary or tertiary amine }\end{array}$ & Proceed to Q-3 & Class III \\
\hline 3 & Does the structure contain elements other than $\mathrm{C}, \mathrm{H}, \mathrm{O}, \mathrm{N}$ or divalent $\mathrm{S}$ ? & Proceed to Q-5 & Proceed to Q-4 \\
\hline 4 & $\begin{array}{l}\text { Do all elements not listed in Q-3 occur only as follows? } \\
\text { (a) } \mathrm{Na}, \mathrm{K}, \mathrm{Ca}, \mathrm{Mg} \text { or ammonium salt of a carboxylic acid } \\
\text { (b) Sulphate or hydrochloride of an amine } \\
\text { (c) } \mathrm{Na}, \mathrm{K} \text {, or Ca salt of sulfonic acid, sulfamic acid, or sulfuric acid }\end{array}$ & Class III & Proceed to Q-7 \\
\hline 5 & Is it a simply branched acyclic aliphatic hydrocarbon or a common carbohydrate? & Proceed to Q-6 & Class I \\
\hline 6 & $\begin{array}{l}\text { Is the substance a benzene derivative bearing substituents consisting only of the } \\
\text { followings? } \\
\text { (a) Hydrocarbon chains or 1'-hydroxy or hydroxy ester-substituted hydrocarbon } \\
\text { chains } \\
\text { (b) One or more alkoxy groups, one of which must be para to the hydrocarbon } \\
\text { chain in (a) }\end{array}$ & Proceed to Q-7 & Class III \\
\hline 7 & Is the substance heterocyclic? & Proceed to Q-16 & Proceed to Q-8 \\
\hline 8 & Is it a lactone or cyclic diester? & Proceed to Q-10 & Proceed to Q-9 \\
\hline 9 & $\begin{array}{l}\text { Is it a lactone fused to another ring, or } 5 \text { - or } 6 \text {-membered } \alpha, \beta \text {-unsaturated lactone? } \\
\text { If a lactone is treated as if it were the hydroxy acid in the form of its more stable } \\
\text { tautomer. } \\
\text { - If it is open chain, } \rightarrow \mathrm{Q}-20 \\
\text { - If it is heterocyclic, } \rightarrow \mathrm{Q}-10 \\
\text { - If it is carboxylic, } \rightarrow \mathrm{Q}-23 \\
\text { If it is a cyclic diester, treat as the separate components }\end{array}$ & $\begin{array}{l}\text { Proceed to Q-20 } \\
\text { Proceed to Q-10 } \\
\text { Proceed to Q-23 }\end{array}$ & Class III \\
\hline 10 & Is it a 3-membered heterocyclic? & Proceed to Q-11 & Class III \\
\hline 11 & $\begin{array}{l}\text { Disregarding only the heteroatoms on any one ring, does that heterocyclic ring } \\
\text { contain or bear substituents other than the followings? } \\
\text { - Simply branched hydrocarbonds } \\
\text { (including bridged chains and monocyclic aryl or alkyl structures) } \\
\text { - Alkyl alcohols, aldehydes, acetals, ketones, ketals, acids } \\
\text { - Esters (including cyclic esters other than lactones) } \\
\text { - Thiols, sulphides, methyl ethers, hydroxy group } \\
\text { - Single rings (hetero or aryl) with no substituents other than those just listed }\end{array}$ & Proceed to Q-12 & Class III \\
\hline 12 & Is the substance heteroaromatic? & Proceed to Q-22 & Proceed to Q-13 \\
\hline 13 & Does the ring bear any substituents? & Class III & Proceed to Q-14 \\
\hline 14 & Does the structure contain more than one aromatic ring? & Proceed to Q-22 & Proceed to Q-15 \\
\hline 15 & $\begin{array}{l}\text { Is it readily hydrolysed to mononuclear residues? } \\
\text { If the answer is YES; } \\
\text { - For the mononuclear heterocylic ridues } \rightarrow \mathrm{Q}-22 \\
\text { - For any carbocyclic residue } \rightarrow \mathrm{Q}-16\end{array}$ & Class III & $\begin{array}{l}\text { Proceed to Q-22 } \\
\text { Proceed to Q-16 }\end{array}$ \\
\hline 16 & $\begin{array}{l}\text { Is it a common terpene-hydrocarbon, -alcohol, -aldehyde or -carboxylic acid } \\
\text { (not a ketone)? }\end{array}$ & Proceed to Q-17 & Class I \\
\hline
\end{tabular}


Appendix 4. Questions for the Structural Class Classification (continued)

\begin{tabular}{|c|c|c|c|}
\hline & \multirow{2}{*}{ Question } & \multicolumn{2}{|c|}{ Reply to the question } \\
\hline & & "No" & "Yes" \\
\hline 17 & $\begin{array}{l}\text { Is the substance readily hydrolysed to a common terpene, terpene-alcohol, -alde- } \\
\text { hyde or -carboxylic acid? } \\
\text { If the answer is YES; } \\
\text { - For the terpene moiety of the hydrolysed residues } \rightarrow \text { Q-18 } \\
\text { - For any non-terpenoid moiety } \rightarrow \mathrm{Q}-19\end{array}$ & Proceed to Q-19 & $\begin{array}{l}\text { proceed to Q.18 } \\
\text { proceed to Q-19 }\end{array}$ \\
\hline
\end{tabular}

18 Is the substance one of the followings:

Class I

Class II
(a) Vicinal diketone; or a ketone or ketal of a ketone attached to a terminal vinyl group
(b) Secondary alcohol or ester of a secondary alcohol attached to a terminal vinyl group
(c) Allyl alcohol or its acetal, ketal or ester derivative
(d) Allyl thiol, allyl sulfide, allyl thioester or allyl amine
(e) Acrolein, methacrolein or their acetals
(f) Acrylic or methacrylic acid
(g) Acetylenic compound
(h) Acyclic aliphatic ketone,ketal or ketoalcohol with no other functional groups and with four or more carbons on either side of the keto group
(i) Substance in which the functional groups are all sterically hindered

19 Is the substance open chain?

Proceed to Q-23 Proceed to Q-20

20 Is the structure a linear or simply branched aliphatic compound, containing any one or combination of only the following functional groups?

Proceed to Q-22 Proceed to Q-21

(a) Four or less, each, of alcohol, aldehyde, carboxylic acid or esters

(b) One each of one or more of the following:

- Acetal

- Either ketone or ketal but not both

- Thiol

- Sulphide (mono- or poly-)

- Thioester, polyoxyethylene $\left[\left(-\mathrm{OCH}_{2} \mathrm{CH}_{2}-\right)_{\mathrm{n}}, n<4\right]$

- Primary or tertiary amine

21 Does the structure contain 3 or more different types of functional groups (exclude Proceed to Q-18 Class III methoxy and consider acids and esters as one functional type)?

\begin{tabular}{|c|c|c|c|}
\hline 22 & $\begin{array}{l}\text { Is the substance a common component of food or structurally closely related to a } \\
\text { common component of food? }\end{array}$ & Class III & Class II \\
\hline 23 & Is the substance aromatic? & Proceed to Q-24 & Proceed to Q-27 \\
\hline 24 & $\begin{array}{l}\text { Is the substance monocarbocyclic (excluding cyclopropane or cyclobutane and their } \\
\text { derivatives) with ring or aliphatic side chains, unsubstituted or containing only one } \\
\text { of the followings? } \\
\text { - Alcohol, aldehyde, side-chain ketone, acid, ester } \\
\text { - Na, K or Ca salt of sulfonic acid } \\
\text { - Na, K or Ca salt of sulfamic acid } \\
\text { - Acyclic acetal or ketal }\end{array}$ & Proceed to Q-25 & Proceed to Q-18 \\
\hline 25 & $\begin{array}{l}\text { Is the substance either of the following? } \\
\text { (a) Cyclopropane or cyclobutane with only the substituents mentioned in Q-24 } \\
\text { (b) Mono- or bicyclic sulphide or thiol }\end{array}$ & Proceed to Q-26 & Class II \\
\hline 26 & $\begin{array}{l}\text { Does the structure contain no functional groups other than those listed in Q- } 24 \\
\text { and is it either a monocycloalkanone or a bicyclic compound with or without a ring } \\
\text { ketone? }\end{array}$ & Proceed to Q-22 & Class II \\
\hline 27 & Do(es) the ring(s) have any substituents? & Class III & Proceed to Q-28 \\
\hline 28 & Does the structure contain more than one aromatic ring? & Proceed to Q-30 & Proceed to Q-29 \\
\hline
\end{tabular}


Appendix 4. Questions for the Structural Class Classification (continued)

\begin{tabular}{|c|c|c|c|}
\hline & \multirow{2}{*}{ Question } & \multicolumn{2}{|c|}{ Reply to the question } \\
\hline & & "No" & "Yes" \\
\hline 29 & $\begin{array}{l}\text { Is it readily hydrolysed to mononuclear residues? } \\
\text { If YES, } \\
\text { - Treat the individual aromatic mononuclear residues } \rightarrow \text { Q-30 } \\
\text { - Treat any other residue } \rightarrow \text { Q-19 }\end{array}$ & Class III & $\begin{array}{l}\text { Proceed to Q-30 } \\
\text { Proceed to Q-19 }\end{array}$ \\
\hline 30 & $\begin{array}{l}\text { Disregarding ring hydroxy or methoxy does the ring bear substituents other than } \\
\text { 1-5-carbon aliphatic groups, either the followings? } \\
\text { - Hydrocarbon } \\
\text { - Alcohol, ketone, aldehyde, carboxy group } \\
\text { - Simple esters that may be hydrolised to ring substituents of } 5 \text { or less carbons } \\
\text { If a simple ester that may be hydrolised, } \\
\text { - Treat the aromatic portion } \rightarrow \mathrm{Q}-18 \\
\text { - Treat the other residue } \rightarrow \mathrm{Q}-19\end{array}$ & $\begin{array}{l}\text { Proceed to Q-18 } \\
\text { Proceed to Q-19 }\end{array}$ & Proceed to Q-31 \\
\hline 31 & $\begin{array}{l}\text { Is the substance an acyclic acetal, -ketal or -ester of any of the above substances } \\
\text { (see Q-30)? } \\
\text { If YES, } \\
\text { - Treat the non-aromatic residues } \rightarrow \text { Q-19 } \\
\text { - Treat the aromatic residue } \rightarrow \text { Q-18 }\end{array}$ & Proceed to Q-32 & $\begin{array}{l}\text { Proceed to Q-19 } \\
\text { Proceed to Q-18 }\end{array}$ \\
\hline 32 & $\begin{array}{l}\text { Does the substance contain only the functional groups listed in Q-30, or their } \\
\text { derivatives listed in Q-31, but with any or all of the following? } \\
\text { (a) Single fused non-aromatic carbocyclic ring } \\
\text { (b) Aliphatic substituent chains longer than } 5 \text { carbon atoms } \\
\text { (c) Polyoxyethylene }\left[\left(-\mathrm{OCH}_{2} \mathrm{CH}_{2}-\right)_{\mathrm{n}}, n<4\right] \text { chain either on the aromatic ring or on } \\
\text { an aliphatic side chain }\end{array}$ & Proceed to Q-22 & Class II \\
\hline
\end{tabular}




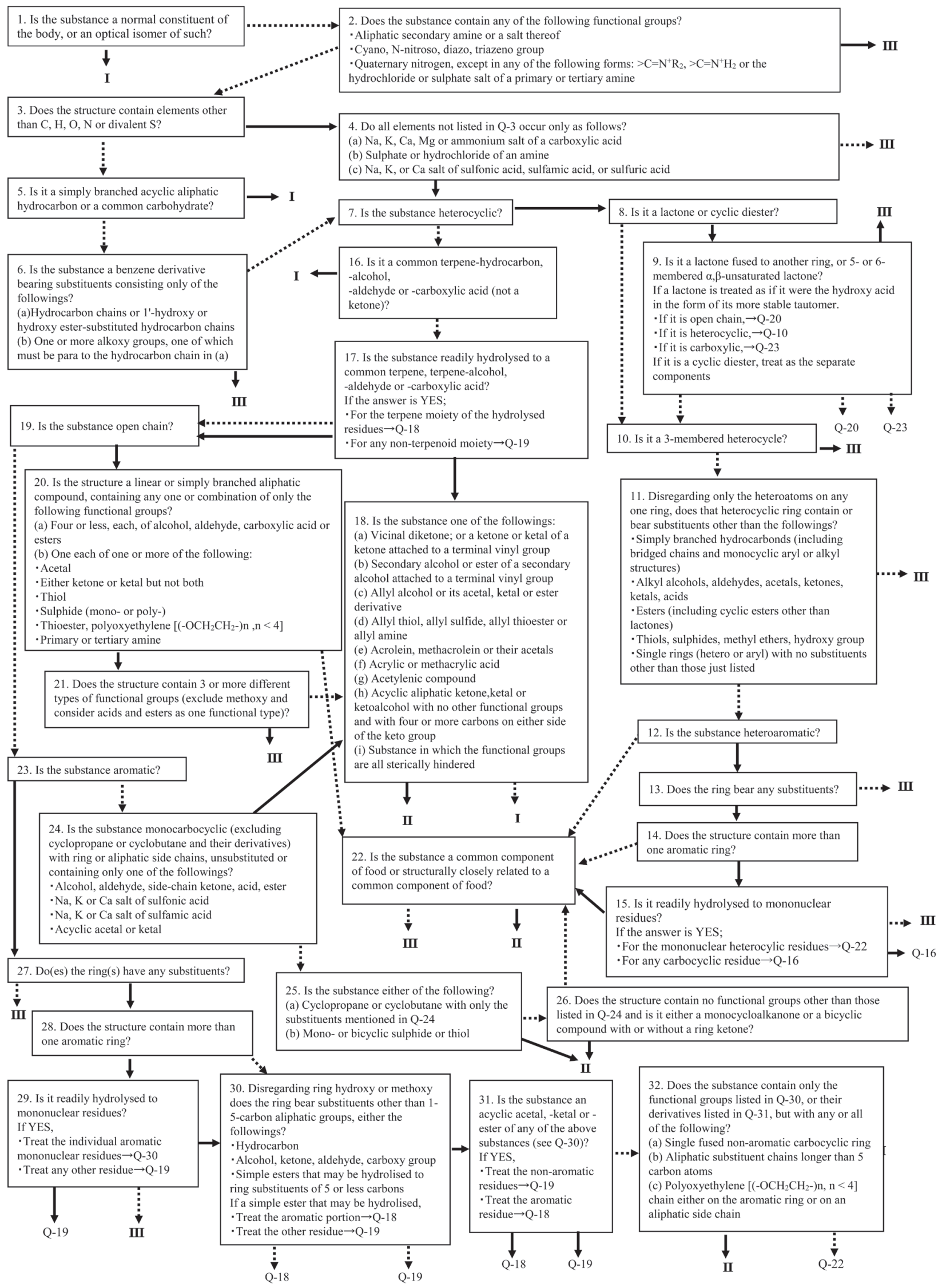

Fig. 3. Structural classification of flavoring substances 


\section{Appendix 5: Structural Class Classification}

Target agents are classified into Structural Class-I, -II and -III below, based on the chemical structure and estimated metabolic pathways, using the questions shown in Appendix $4^{1,2,8)}$.

\section{Class I}

Substances of simple chemical structure and efficient modes of metabolism which would suggest a low order of oral toxicity (e.g., isoamyl butyrate).

\section{Class II}

Contains structures that are intermediate between Class I and Class III. They possess structures that are less innocuous than substances in Class I, but do not contain structural features suggestive of toxicity like those substances in Class III. Members of Class II may contain reactive functional groups (e.g., furfuryl alcohol).

\section{Class III}

Substances of a chemical structure that permit no strong initial presumption of safety, or that may even suggest significant toxicity (e.g., 2-phenyl-3-carbethoxy furan and benzoin). 


\section{Appendix 6: Basis of Human Exposure Threshold of Each Structural Class}

The human exposure threshold was calculated by multiplying the 5th percentile NOEL by 60 (assuming an individual weighs $60 \mathrm{~kg}$ ) and dividing by a safety factor of 100. The human exposure threshold of each Structural Class is summarized in Table 1.

The human exposure threshold was calculated from the cumulative distribution of NOELs of each Structural Class derived from around 3,000 entries of data on toxicity, including general toxicity, carcinogenicity, reproductive and developmental toxicity, and neurotoxicity, concerning around 600 substances, including industrial chemicals, pesticides, and food additives. Fig. 4 shows cumulative distributions of NOELs derived from the toxicological data.

Table 1. Human exposure threshold of each Structural Class ${ }^{1,2,6)}$

\begin{tabular}{ccc}
\hline Structural Class & $\begin{array}{c}5^{\text {th }} \text { percentile NOEL } \\
(\mu \mathrm{g} / \mathrm{kg} \text { bw/day })\end{array}$ & $\begin{array}{c}\text { Human exposure threshold } \\
(\mu \mathrm{g} / \text { person/day })\end{array}$ \\
\hline I & 2,993 & 1,800 \\
II & 906 & 540 \\
III & 147 & 90 \\
\hline
\end{tabular}

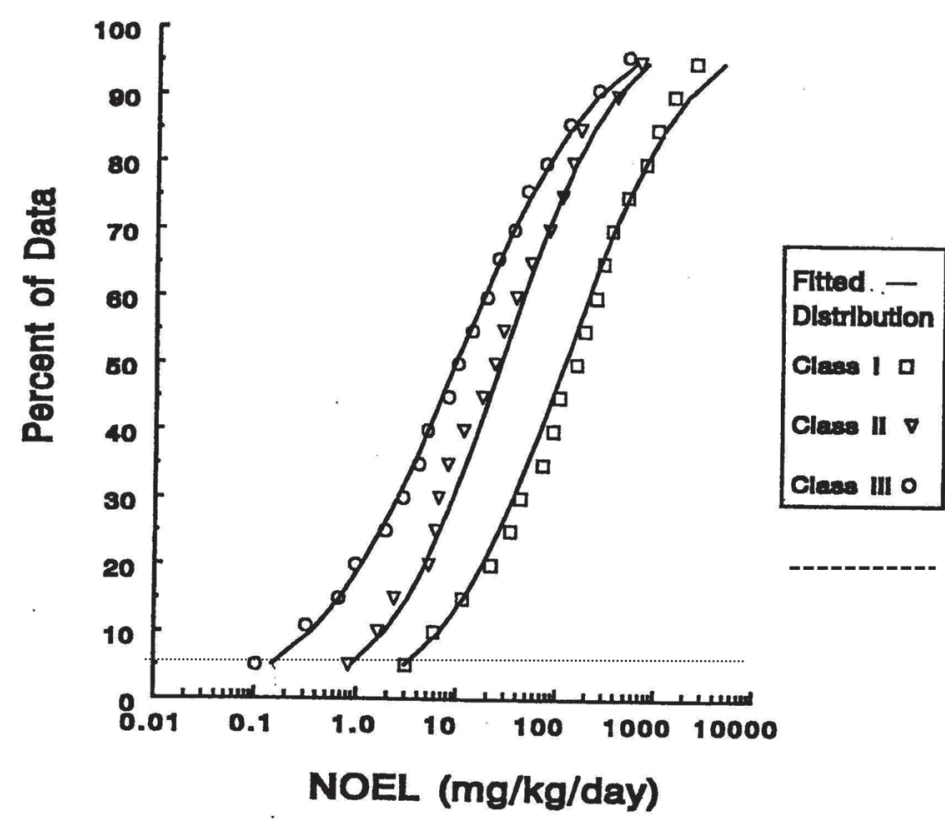

Fig. 4. Cumulative distributions of NOELs derived from toxicological data 


\section{References}

1. Assessment Procedures regarding internationally commonly used Flavors (the final report, the revised version) (November 4 , 2003).

2. WHO. Food Additives Series 35, Toxicological evaluation of certain food additives and contaminants, prepared by the 44th meeting of the Joint FAO/WHO Expert Committee on Food Additives, Rome, 14-23 February 1995, WHO, Geneva, 1996; Annex5: 425-59.

3. EFSA. Panel on Food Contact Materials, Enzymes, Flavourings and Processing Aids (CEF), EFSA Scientific Opinion, Guidance on the data required for the risk assessment of flavourings to be used in or on foods, 2010.

4. Takeshi Yamazaki et. al. Study on the procedure for the risk assessment of flavorings in Japan, Research and Survey Program (No. 1401), March, 2015.

5. WHO. Food Additives Series 60, Safety evaluation of certain food additives and contaminants, prepared by the 69th meeting of the Joint FAO/WHO Expert Committee on Food Additives, Rome, 17-26 June 2008, WHO, Geneva, 2009: 268-89.

6. Munro IC, Ford RA, Kennepohl E, Sprenger JG. Correlation of structural class with no-observed-effect levels: a proposal for establishing a threshold of concern. Food Chem Toxicol. 1996; 34: 829-867. [Medline]

7. FSCJ. Guideline for Assessment of the Effect of Food on Human Health Regarding Food Additives (May 27, 2010).

8. Cramer GM, Ford RA, Hall RL. Estimation of toxic hazard-a decision tree approach. Food and Cosmetics Toxicology. 1978; 16: 255-276. [Medline]

9. WHO. Food Additives Series 40, Safety evaluation of certain food additives and contaminants, prepared by the 49th meeting of the Joint FAO/WHO Expert Committee on Food Additives, Rome, 17-26 June 1997, WHO, Geneva, 1998; Annex5.

10. EFSA. Panel on Food Contact Materials, Enzymes, Flavourings and Processing Aids (CEF), EFSA Scientific Opinion, Flavouring Group Evaluation 01, Revision 2 (FGE.01Rev2): Branched-chain aliphatic saturated aldehydes, carboxylic acids and related esters of primary alcohols and branched-chain carboxylic acids from chemical groups 1 and 2, 2010.

11. EFSA. Panel on Food Additives, Flavourings, Processing Aids and Materials in Contact with Food (AFC), EFSA Scientific Opinion, Flavouring Group Evaluation 02, Revision 1 (FGE.02Rev1): Branched- and straight-chain aliphatic saturated primary alcohols and related esters of primary alcohols and straight-chain carboxylic acids and one straight-chain aldehyde from chemical groups 1 and 2, 2008.

12. EFSA. Panel on Food Contact Materials, Enzymes, Flavourings and Processing Aids (CEF), EFSA Scientific Opinion, Flavouring Group Evaluation 03, Revision 2 (FGE.03Rev2): Acetals of branched- and straight-chain aliphatic saturated primary alcohols and branched- and straight-chain saturated or unsaturated aldehydes, an ester of a hemiacetal and an orthoester of formic acid, from chemical groups 1, 2 and 4, 2011.

13. EFSA. Panel on Food Additives, Flavourings, Processing Aids and Materials in Contact with Food (AFC), EFSA Scientific Opinion, Flavouring Group Evaluation 04, (FGE.04): 2-Ethylhexyl derivatives from chemical group 2, 2008.

14. EFSA. Panel on Food Contact Materials, Enzymes, Flavourings and Processing Aids (CEF), EFSA Scientific Opinion, Flavouring Group Evaluation 05, Revision 2 (FGE.05Rev2): Branched- and straight-chain unsaturated carboxylic acids and esters of these with aliphatic saturated alcohols from chemical groups 1, 2, 3 and 5, 2010.

15. EFSA. Panel on Food Contact Materials, Enzymes, Flavourings and Processing Aids (CEF), EFSA Scientific Opinion, Flavouring Group Evaluation 06, Revision 4 (FGE.06Rev4): Straight- and branched-chain aliphatic unsaturated primary alcohols, aldehydes, carboxylic acids and esters from chemical groups 1,3 and 4, 2013.

16. EFSA. Panel on Food Contact Materials, Enzymes, Flavourings and Processing Aids (CEF), EFSA Scientific Opinion, Flavouring Group Evaluation 07, Revision 4 (FGE.07Rev4): Saturated and unsaturated aliphatic secondary alcohols, ketones and esters of secondary alcohols and saturated linear or branched-chain carboxylic acids from chemical group 5, 2012.

17. EFSA. Panel on Food Contact Materials, Enzymes, Flavourings and Processing Aids (CEF), EFSA Scientific Opinion, Flavouring Group Evaluation 08, Revision 5 (FGE.08Rev5): Aliphatic and alicyclic mono-, di-, tri-, and polysulphides with or without additional oxygenated functional groups from chemical groups 20 and 30, 2012.

18. EFSA. Panel on Food Contact Materials, Enzymes, Flavourings and Processing Aids (CEF), EFSA Scientific Opinion, Flavouring Group Evaluation 09, Revision 5 (FGE.09Rev5): Secondary alicyclic saturated and unsaturated alcohols, ketones and esters containing secondary alicyclic alcohols from chemical group 8 and 30, and an ester of a phenol derivative from chemical group $25,2010$.

19. EFSA. Panel on Food Contact Materials, Enzymes, Flavourings and Processing Aids (CEF), EFSA Scientific Opinion, Flavouring Group Evaluation 10, Revision 3 (FGE.10Rev3): Aliphatic primary and secondary saturated and unsaturated alcohols, aldehydes, acetals, carboxylic acids and esters containing an additional oxygenated functional group and lactones from chemical groups 9, 13 and 30, 2012.

20. EFSA. Panel on Food Contact Materials, Enzymes, Flavourings and Processing Aids (CEF), EFSA Scientific Opinion, Flavouring Group Evaluation 11, Revision 3 (FGE.11Rev3): Aliphatic dialcohols, diketones, and hydroxyketones from chemical groups 8 and $10,2014$.

21. EFSA. Panel on Food Contact Materials, Enzymes, Flavourings and Processing Aids (CEF), EFSA Scientific Opinion, Flavouring Group Evaluation 12, Revision 5 (FGE.12Rev5): Primary saturated or unsaturated alicyclic alcohol, aldehyde, acid, and esters from chemical groups 1, 7 and 8, 2014.

22. EFSA. Panel on Food Contact Materials, Enzymes, Flavourings and Processing Aids (CEF), EFSA Scientific Opinion, Flavouring Group Evaluation 13, Revision 2 (FGE.13Rev2): Furfuryl and furan derivatives with and without additional side-chain substituents and heteroatoms from chemical group 14, 2011. 
23. EFSA. Panel on Food Additives, Flavourings, Processing Aids and Materials in Contact with Food (AFC), EFSA Scientific Opinion, Flavouring Group Evaluation 14, Revision 2 (FGE.14Rev2): Phenethyl alcohol, aldehyde, acetals, carboxylic acid and related esters from chemical group 15 and 22, 2009.

24. EFSA. Panel on Food Contact Materials, Enzymes, Flavourings and Processing Aids (CEF), EFSA Scientific Opinion, Flavouring Group Evaluation 15, Revision 2 (FGE.15Rev2): Aryl-substituted saturated and unsaturated primary alcohol/aldehyde/acid/ ester derivatives from chemical group 22, 2011.

25. EFSA. Panel on Food Contact Materials, Enzymes, Flavourings and Processing Aids (CEF), EFSA Scientific Opinion, Flavouring Group Evaluation 16, Revision 2 (FGE.16Rev2): Aromatic ketones from chemical group 21, 2009.

26. EFSA. Panel on Food Contact Materials, Enzymes, Flavourings and Processing Aids (CEF), EFSA Scientific Opinion, Flavouring Group Evaluation 17, Revision 3 (FGE.17Rev3): Pyrazine derivatives from chemical group 24, 2011.

27. EFSA. Panel on Food Contact Materials, Enzymes, Flavourings and Processing Aids (CEF), EFSA Scientific Opinion, Flavouring Group Evaluation 18, Revision 3 (FGE.18Rev3): Aliphatic, alicyclic and aromatic saturated and unsaturated tertiary alcohols, aromatic tertiary alcohols and their esters from chemical groups 6 and 8, 2015.

28. EFSA. Panel on Food Contact Materials, Enzymes, Flavourings and Processing Aids (CEF), EFSA Scientific Opinion, Flavouring Group Evaluation 20, Revision 4 (FGE.20Rev4): Benzyl alcohols, benzaldehydes, a related acetal, benzoic acids, and related esters from chemical groups 23 and 30, 2012.

29. EFSA. Panel on Food Contact Materials, Enzymes, Flavourings and Processing Aids (CEF), EFSA Scientific Opinion, Flavouring Group Evaluation 21, Revision 5 (FGE.21Rev5): Thiazoles, thiophenes, thiazoline and thienyl derivatives from chemical groups 29 and 30, 2015.

30. EFSA. Panel on Food Contact Materials, Enzymes, Flavourings and Processing Aids (CEF), EFSA Scientific Opinion, Flavouring Group Evaluation 22, Revision 1 (FGE.22Rev1): Ring-substituted phenolic substances from chemical groups 21 and 25 , 2011.

31. EFSA. Panel on Food Contact Materials, Enzymes, Flavourings and Processing Aids (CEF), EFSA Scientific Opinion, Flavouring Group Evaluation 23, Revision 4 (FGE.23Rev4): Aliphatic, alicyclic and aromatic ethers including anisole derivatives from chemical groups 15, 16, 22, 26 and 30, 2013.

32. EFSA. Panel on Food Contact Materials, Enzymes, Flavourings and Processing Aids (CEF), EFSA Scientific Opinion, Flavouring Group Evaluation 24, Revision 2 (FGE.24Rev2): Pyridine, pyrrole, indole and quinoline derivatives from chemical group 28, 2013.

33. EFSA. Panel on Food Contact Materials, Enzymes, Flavourings and Processing Aids (CEF), EFSA Scientific Opinion, Flavouring Group Evaluation 25, Revision 3 (FGE.25Rev3): Aliphatic hydrocarbons from chemical group 31, 2015.

34. EFSA. Panel on Food Additives, Flavourings, Processing Aids and Materials in Contact with Food (AFC), EFSA Scientific Opinion, Flavouring Group Evaluation 26, (FGE. 26): Amino acids from chemical group 34, 2006.

35. EFSA. Panel on Food Additives, Flavourings, Processing Aids and Materials in Contact with Food (AFC), EFSA Scientific Opinion, Flavouring Group Evaluation 27, (FGE.27): One aromatic lactone from chemical group 11, 2008.

36. EFSA. Panel on Food Additives, Flavourings, Processing Aids and Materials in Contact with Food (AFC), EFSA Scientific Opinion, Flavouring Group Evaluation 29, (FGE.29): Substance from the priority list: Vinylbenzene from chemical group 31, 2009.

37. EFSA. Panel on Food Contact Materials, Enzymes, Flavourings and Processing Aids (CEF), EFSA Scientific Opinion, Flavouring Group Evaluation 30, Revision 1 (FGE.30Rev1): 4-Prop-1-enylphenol and 2-methoxy-4-(prop-1-enyl)phenyl 3-methylbutyrate from chemical group 17, 2011.

38. EFSA. Panel on Food Additives, Flavourings, Processing Aids and Materials in Contact with Food (AFC), EFSA Scientific Opinion, Flavouring Group Evaluation 31 (FGE.31): One Epoxide from Chemical Group 32, 2008.

39. EFSA. Panel on Food Contact Materials, Enzymes, Flavourings and Processing Aids (CEF), EFSA Scientific Opinion, Flavouring Group Evaluation 32, (FGE.32): Flavonoids (Flavanones and dihydrochalcones) from chemical groups 25 and 30, 2010.

40. EFSA. Panel on Food Additives, Flavourings, Processing Aids and Materials in Contact with Food (AFC), EFSA Scientific Opinion, Flavouring Group Evaluation 33, (FGE.33): Six Tetrahydrofuran Derivatives From Chemical Groups 13, 14, 16 and 26, 2008.

41. EFSA. Panel on Food Additives, Flavourings, Processing Aids and Materials in Contact with Food (AFC), EFSA Scientific Opinion, Flavouring Group Evaluation 34, (FGE.34): One tetrahydroquinoline derivative from chemical group 28, 2008.

42. EFSA. Panel on Food Additives, Flavourings, Processing Aids and Materials in Contact with Food (AFC), EFSA Scientific Opinion, Flavouring Group Evaluation 35, (FGE.35): Three quinine salts from the Priority list from chemical group 30, 2008.

43. EFSA. Panel on Food Additives, Flavourings, Processing Aids and Materials in Contact with Food (AFC), EFSA Scientific Opinion, Flavouring Group Evaluation 36, (FGE.36): Two triterpene glycosides from the priority list, 2008.

44. EFSA. Panel on Food Additives, Flavourings, Processing Aids and Materials in Contact with Food (AFC), EFSA Scientific Opinion, Flavouring Group Evaluation 38, (FGE38): 3-Butenyl isothiocyanate, 2008.

45. EFSA. Panel on Food Contact Materials, Enzymes, Flavourings and Processing Aids (CEF), EFSA Scientific Opinion, Flavouring Group Evaluation 40, (FGE.40): An aromatic derivative of 2-hydroxy-propionamide. Chemical group 16, 2010.

46. EFSA. Panel on Food Contact Materials, Enzymes, Flavourings and Processing Aids (CEF), EFSA Scientific Opinion, Flavouring Group Evaluation 42, (FGE.42): Ion containing organic substances from chemical group 30, 2009.

47. EFSA. Panel on Food Contact Materials, Enzymes, Flavourings and Processing Aids (CEF), EFSA Scientific Opinion, Flavouring Group Evaluation 43, (FGE.43): Thujyl alcohol from chemical group 8, 2009. 
48. EFSA. Panel on Food Additives, Flavourings, Processing Aids and Materials in Contact with Food (AFC), EFSA Scientific Opinion, Flavouring Group Evaluation 44, (FGE.44): cis-2-Heptyl-cyclopropanecarboxylic Acid from Chemical Group 30, 2011.

49. EFSA. Panel on Food Additives, Flavourings, Processing Aids and Materials in Contact with Food (AFC), EFSA Scientific Opinion, Flavouring Group Evaluation 45, (FGE.45): One tertiary amine from chemical group 28, 2009.

50. EFSA. Panel on Food Contact Materials, Enzymes, Flavourings and Processing Aids (CEF), EFSA Scientific Opinion, Flavouring Group Evaluation 46, Revision 1 (FGE.46Rev1): Ammonia and three ammonium salts from chemical group 30, 2011.

51. EFSA. Panel on Food Contact Materials, Enzymes, Flavourings and Processing Aids (CEF), EFSA Scientific Opinion, Flavouring Group Evaluation 47, Revision 1 (FGE.47Rev1): Bi- and tricyclic secondary alcohols, ketones and related esters from chemical group 8, 2012.

52. EFSA. Panel on Food Additives, Flavourings, Processing Aids and Materials in Contact with Food (AFC), EFSA Scientific Opinion, Flavouring Group Evaluation 48, (FGE.48): Aminoacetophenone from chemical group 33, 2008.

53. EFSA. Panel on Food Additives, Flavourings, Processing Aids and Materials in Contact with Food (AFC), EFSA Scientific Opinion, Flavouring Group Evaluation 49, (FGE.49): Xanthin alkaloids from the Priority list from chemical group 30, 2008.

54. EFSA. Panel on Food Contact Materials Enzymes, Flavourings and Processing Aids (CEF), EFSA Scientific Opinion, Flavouring Group Evaluation 50, Revision 1 (FGE.50Rev1): Consideration of pyrazine derivatives evaluated by JECFA (57th meeting) structurally related to pyrazine derivatives evaluated by EFSA in FGE.17Rev2 (2010), 2011.

55. EFSA. Panel on Food Contact Materials Enzymes, Flavourings and Processing Aids (CEF), EFSA Scientific Opinion, Flavouring Group Evaluation 51, Revision 1 (FGE.51Rev1): Consideration of alicyclic ketones and secondary alcohols and related esters evaluated by the JECFA (59th meeting) structurally related to alicyclic ketones secondary alcohols and related esters in FGE.09Rev3 (2011), 2012.

56. EFSA. Panel on Food Additives Flavourings, Processing Aids and Materials in Contact with Food (AFC), EFSA Scientific Opinion, Flavouring Group Evaluation 52, (FGE.52): Consideration of hydroxy- and alkoxy-substituted benzyl derivatives evaluated by JECFA (57th meeting) structurally related to benzyl alcohols, benzaldehydes, a related acetal, benzoic acids, and related esters evaluated by EFSA in FGE.20 (2005) (Commission Regulation (EC) No 1565/2000 of 18 July 2000 ), 2008.

57. EFSA. Panel on Food Contact Materials Enzymes, Flavourings and Processing Aids (CEF), EFSA Scientific Opinion, Flavouring Group Evaluation 53, Revision 1 (FGE.53Rev1): Consideration of phenethyl alcohol, aldehyde, acid and related acetals and esters evaluated by JECFA (59th meeting) and structurally related to phenethyl alcohol, aldehyde, esters and related phenylacetic acid esters evaluated by EFSA in FGE.14Rev1 (2009) and one phenoxyethyl ester evaluated in FGE.23Rev1 (2008), 2009.

58. EFSA. Panel on Food Contact Materials Enzymes, Flavourings and Processing Aids (CEF), EFSA Scientific Opinion, Flavouring Group Evaluation 54, Revision 1 (FGE.54Rev1): Consideration of benzyl derivatives evaluated by JECFA (57th meeting) structurally related to benzyl alcohols, benzaldehydes, a related acetal, benzoic acids and related esters evaluated by EFSA in FGE.20Rev1 (2009), 2009.

59. EFSA. Panel on Food Additives Flavourings, Processing Aids and Materials in Contact with Food (AFC), EFSA Scientific Opinion, Flavouring Group Evaluation 55, (FGE.55): Consideration of phenyl-substituted aliphatic alcohols and related aldehydes and esters evaluated by JECFA (63rd meeting) structurally related to phenethyl alcohol, aldehyde, esters and related phenylacetic acid esters evaluated by EFSA in FGE.14 (2005) and aryl-substituted saturated and unsaturated primary alcohol/ aldehyde/acid/ester derivatives evaluated by EFSA in FGE.15 (2005) (Commission Regulation (EC) No 1565/2000 of 18 July 2000), 2008.

60. EFSA. Panel on Food Additives Flavourings, Processing Aids and Materials in Contact with Food (AFC), EFSA Scientific Opinion, Flavouring Group Evaluation 56, (FGE.56): Consideration of monocyclic and alcohols, ketones and related esters evaluated by JECFA (63rd meeting) structurally related to secondary alicyclic saturated and unsaturated alcohols, ketones and esters containing secondary alicyclic alcohols and an ester of a phenol carboxylic acid evaluated by EFSA in FGE.09Rev1 (2008), 2008.

61. EFSA. Panel on Food Contact Materials Enzymes, Flavourings and Processing Aids (CEF), EFSA Scientific Opinion, Flavouring Group Evaluation 57, (FGE.57): Consideration of two structurally related pulegone metabolites and one ester thereof evaluated by JECFA (55th meeting), 2009.

62. EFSA. Panel on Food Additives Flavourings, Processing Aids and Materials in Contact with Food (AFC), EFSA Scientific Opinion, Flavouring Group Evaluation 58, (FGE.58): Consideration of phenol derivatives evaluated by JECFA (55th meeting) structurally related to ring substituted phenolic substances evaluated by EFSA in FGE.22 (2006) (Commission Regulation (EC) No 1565/2000 of 18 July 2000), 2008.

63. EFSA. Panel on Food Contact Materials Enzymes, Flavourings and Processing Aids (CEF), EFSA Scientific Opinion, Flavouring Group Evaluation 59, Revision 1 (FGE.59Rev1): Consideration of aliphatic and aromatic ethers evaluated by JECFA (61st meeting and 63rd meeting) structurally related to aliphatic, alicyclic and aromatic ethers including anisole derivatives evaluated by EFSA in FGE.23 Rev2 (2010), 2011.

64. EFSA. Panel on Food Additives Flavourings, Processing Aids and Materials in Contact with Food (AFC), EFSA Scientific Opinion, Flavouring Group Evaluation 60, (FGE.60): Consideration of eugenol and related hydroxyallylbenzene derivatives evaluated by JECFA (65th meeting) structurally related to ring-substituted phenolic substances evaluated by EFSA in FGE.22 (2006), 2009.

65. EFSA. Panel on Food Contact Materials Enzymes, Flavourings and Processing Aids (CEF), EFSA Scientific Opinion, Flavouring Group Evaluation 61, Revision 1 (FGE.61Rev1): Consideration of aliphatic acetals evaluated by JECFA (57th meeting) structurally related to acetals of branched- and straight-chain aliphatic saturated primary alcohols and branched- and straightchain saturated aldehydes and one orthoester of formic acid evaluated by EFSA in FGE.03Rev1 (2008), 2009. 
66. EFSA. Panel on Food Contact Materials Enzymes, Flavourings and Processing Aids (CEF), EFSA Scientific Opinion, Flavouring Group Evaluation 62, Revision 1 (FGE.62Rev1): Consideration of of linear and branched-chain aliphatic unsaturated, unconjugated alcohols, aldehydes, acids, and related esters evaluated by JECFA (61st and 68th meeting) structurally related to branched- and straight-chain unsaturated carboxylic acids and esters of these with aliphatic saturated alcohols evaluated by EFSA in FGE.05Rev2 (2010) and to straight- and branched-chain aliphatic unsaturated primary alcohols, aldehydes, carboxylic acids, and esters evaluated by EFSA in FGE.06Revl (2008), 2008.

67. EFSA. Panel on Food Contact Materials, Enzymes, Flavourings and Processing Aids (CEF), EFSA Scientific Opinion, Flavouring Group Evaluation 63, Revision 2 (FGE63Rev2): Consideration of aliphatic secondary alcohols, ketones and related esters evaluated by JECFA (59th and 69th meetings) structurally related to saturated and unsaturated aliphatic secondary alcohols, ketones and esters of secondary alcohols and saturated linear or branched-chain carboxylic acids evaluated by EFSA in FGE.07Rev4, 2013.

68. EFSA. Panel on Food Additives Flavourings, Processing Aids and Materials in Contact with Food (AFC), EFSA Scientific Opinion, Flavouring Group Evaluation 64, (FGE64): Consideration of aliphatic acyclic diols, triols, and related substances evaluated by JECFA (57th meeting) structurally related to aliphatic primary and secondary saturated and unsaturated alcohols, aldehydes, acetals, carboxylic acids and esters containing an additional oxygenated functional group and lactones from chemical groups 9, 13 and 30 evaluated by EFSA in FGE.10Rev1 (EFSA, 2008ab), 2009.

69. EFSA. Panel on Food Contact Materials Enzymes, Flavourings and Processing Aids (CEF), EFSA Scientific Opinion, Flavouring Group Evaluation 65, Revision 1 (FGE.65Rev1): Consideration of sulfur-substituted furan derivatives used as flavouring agents evaluated by JECFA (59th meeting) structurally related to a subgroup of substances within the group of 'Furfuryl and furan derivatives with and without additional side-chain substituents and heteroatoms from chemical group 14' evaluated by EFSA in FGE.13Rev2 (2011), 2015.

70. EFSA. Panel on Food Contact Materials Enzymes, Flavourings and Processing Aids (CEF), EFSA Scientific Opinion, Flavouring Group Evaluation 66, Revision 1 (FGE.66Rev1): Consideration of Furfuryl Alcohol and Related Flavouring Substances Evaluated by JECFA (55th meeting), 2011.

71. EFSA. Panel on Food Contact Materials, Enzymes, Flavourings and Processing Aids (CEF), EFSA Scientific Opinion, Flavouring Group Evaluation 67, Revision 2 (FGE.67Rev2): Consideration of 28 furan-substituted compounds evaluated by JECFA at the 55th, 65th and 69th meetings (JECFA, 2001, 2006a, 2009b), 2015.

72. EFSA. Panel on Food Contact Materials Enzymes, Flavourings and Processing Aids (CEF), EFSA Scientific Opinion, Flavouring Group Evaluation 68, (FGE.68): Consideration of cinnamyl alcohol and related flavouring agents evaluated by JECFA (55th meeting) structurally related to aryl-substituted saturated and unsaturated primary alcohol/aldehyde/acid/ester derivatives evaluated by EFSA in FGE.15Rev1 (2008)1, 2009.

73. EFSA. Panel on Food Additives Flavourings, Processing Aids and Materials in Contact with Food (AFC), EFSA Scientific Opinion, Flavouring Group Evaluation 69, (FGE.69): Consideration of aromatic substituted secondary alcohols, ketones and related esters evaluated by JECFA (57th meeting) structurally related to aromatic ketones from chemical group 21 evaluated by EFSA in FGE.16 (2006), 2008.

74. EFSA. Panel on Food Contact Materials Enzymes, Flavourings and Processing Aids (CEF), EFSA Scientific Opinion, Flavouring Group Evaluation 70, (FGE.70): Consideration of aliphatic, alicyclic, linear, alpha,beta-unsaturated, di- and trienals and related alcohols, acids and esters evaluated by JECFA (61st meeting), 2009.

75. EFSA. Panel on Food Contact Materials Enzymes, Flavourings and Processing Aids (CEF), EFSA Scientific Opinion, Flavouring Group Evaluation 71, (FGE.71): Consideration of aliphatic, linear, alpha,beta-unsaturated carboxylic acids and related esters evaluated by JECFA (63rd meeting) structurally related to esters of branched- and straight-chain unsaturated carboxylic acids. Esters of these and straight-chain aliphatic saturated alcohols evaluated by in FGE.05Rev2 (2009), 2010.

76. EFSA. Panel on Food Contact Materials Enzymes, Flavourings and Processing Aids (CEF), EFSA Scientific Opinion, Flavouring Group Evaluation 72, Revision 1 (FGE.72Rev1): Consideration of aliphatic, branched-chain saturated and unsaturated alcohols, aldehydes, acids, and related esters evaluated by the JECFA (61st meeting) structurally related to branched- and straight-chain unsaturated carboxylic acids, esters of these and straight-chain aliphatic saturated alcohols evaluated by EFSA in FGE.05Rev2, 2013.

77. EFSA. Panel on Food Contact Materials Enzymes, Flavourings and Processing Aids (CEF), EFSA Scientific Opinion, Flavouring Group Evaluation 73, Revision 3 (FGE.73Rev3): Consideration of alicyclic alcohols, aldehydes, acids and related esters evaluated by JECFA (59th and 63rd meeting) structurally related to primary saturated or unsaturated alicyclic alcohols, aldehydes, acids and esters evaluated by EFSA in FGE.12Rev4 (2013), 2014.

78. EFSA. Panel on Food Contact Materials Enzymes, Flavourings and Processing Aids (CEF), EFSA Scientific Opinion, Flavouring Group Evaluation 74, Revision 3 (FGE.74Rev3): Consideration of Simple Aliphatic Sulphides and Thiols evaluated by the JECFA (53rd and 61st meeting) Structurally related to Aliphatic and Alicyclic Mono-, Di-, Tri-, and Polysulphides with or without Additional Oxygenated Functional Groups from Chemical Group 20 evaluated by EFSA in FGE.08Rev5 (2012), 2010.

79. EFSA. Panel on Food Additives Flavourings, Processing Aids and Materials in Contact with Food (AFC), EFSA Scientific Opinion, Flavouring Group Evaluation 75, (FGE.75): Consideration of tetrahydrofuran derivatives and a furanone derivative evaluated by JECFA (63rd meeting) structurally related to tetrahydrofuran derivatives evaluated by EFSA in FGE.33 (2008), 2008.

80. EFSA. Panel on Food Contact Materials Enzymes, Flavourings and Processing Aids (CEF), EFSA Scientific Opinion, Flavouring Group Evaluation 76, Revision 1 (FGE.76Rev1): Consideration of sulphur-containing heterocyclic compounds evaluated by JECFA (59th meeting) structurally related to thiazoles, thiophene, thiazoline and thienyl derivatives from chemical group 29 and miscellaneous substances from chemical group 30 evaluated by EFSA in FGE.21Rev3, 2013. 
81. EFSA. Panel on Food Contact Materials Enzymes, Flavourings and Processing Aids (CEF), EFSA Scientific Opinion, Flavouring Group Evaluation 77, Revision 2 (FGE.77): Consideration of Pyridine, Pyrrole and Quinoline Derivatives evaluated by JECFA (63rd meeting) structurally related to Pyridine, Pyrrole, Indole and Quinoline Derivatives evaluated by EFSA in FGE.24Rev2 (2013), 2015.

82. EFSA. Panel on Food Contact Materials Enzymes, Flavourings and Processing Aids (CEF), EFSA Scientific Opinion, Flavouring Group Evaluation 78, Revision 2 (FGE.78Rev2): Consideration of aliphatic and alicyclic and aromatic hydrocarbons evaluated by JECFA (63rd meeting) structurally related to aliphatic hydrocarbons evaluated by EFSA in FGE.25Rev3, 2015.

83. EFSA. Panel on Food Additives Flavourings, Processing Aids and Materials in Contact with Food (AFC), EFSA Scientific Opinion, Flavouring Group Evaluation 79, (FGE.79): Consideration of amino acids and related substances evaluated by JECFA (63rd meeting) structurally related to amino acids from chemical group 34 evaluated by EFSA in FGE.26Rev1 (2008), 2008.

84. EFSA. Panel on Food Contact Materials Enzymes, Flavourings and Processing Aids (CEF), EFSA Scientific Opinion, Flavouring Group Evaluation 80, Revision 1 (FGE.80Rev1): Consideration of alicyclic, alicyclic-fused and aromatic-fused ring lactones evaluated by JECFA (61st meeting) structurally related to a aromatic lactone evaluated by EFSA in FGE.27 (2008), 2009.

85. EFSA. Panel on Food Contact Materials Enzymes, Flavourings and Processing Aids (CEF), EFSA Scientific Opinion, Flavouring Group Evaluation 81, (FGE.81): Consideration of hydroxypropenylbenzenes evaluated by JECFA (61st meeting) structurally related to 2-methoxy-4-(prop-1-enyl)phenyl 3-methylbutyrate from chemical group 17 evaluated by EFSA in FGE.30, 2010.

86. EFSA. Panel on Food Contact Materials Enzymes, Flavourings and Processing Aids (CEF), EFSA Scientific Opinion, Flavouring Group Evaluation 82, Revision 1 (FGE.82Rev1): Consideration of Epoxides evaluated by the JECFA (65th meeting), 2014.

87. EFSA. Panel on Food Contact Materials Enzymes, Flavourings and Processing Aids (CEF), EFSA Scientific Opinion, Flavouring Group Evaluation 83, Revision 1 (FGE.83Rev1): Consideration of ethyl maltol and two 6-keto-1,4-dioxane derivatives substances evaluated by JECFA (65th meeting), 2010.

88. EFSA. Panel on Food Additives Flavourings, Processing Aids and Materials in Contact with Food (AFC), EFSA Scientific Opinion, Flavouring Group Evaluation 84, (FGE.84): Consideration of Anthranilate derivatives evaluated by JECFA (65th meeting), 2008.

89. EFSA. Panel on Food Contact Materials Enzymes, Flavourings and Processing Aids (CEF), EFSA Scientific Opinion, Flavouring Group Evaluation 85, (FGE.85): Consideration of miscellaneous nitrogen-containing substances evaluated by JECFA (65th meeting), 2008.

90. EFSA. Panel on Food Contact Materials Enzymes, Flavourings and Processing Aids (CEF), EFSA Scientific Opinion, Flavouring Group Evaluation 86, Revision 2 (FGE.86Rev2): Consideration of aliphatic and arylalkyl amines and amides evaluated by JECFA (65th meeting), 2015.

91. EFSA. Panel on Food Contact Materials Enzymes, Flavourings and Processing Aids (CEF), EFSA Scientific Opinion, Flavouring Group Evaluation 87, Revision 2 (FGE.87Rev2): Consideration of bicyclic secondary alcohols, ketones and related esters evaluated by JECFA (63rd meeting) structurally related to bicyclic secondary alcohols, ketones and related esters evaluated by EFSA in FGE.47Rev1 (2008), 2014.

92. EFSA. Panel on Food Additives Flavourings, Processing Aids and Materials in Contact with Food (AFC), EFSA Scientific Opinion, Flavouring Group Evaluation 88, (FGE.88): Consideration of Phenol and Phenol Derivatives evaluated by JECFA (55th meeting), 2014.

93. EFSA. Panel on Food Contact Materials, Enzymes, Flavourings and Processing Aids (CEF), EFSA Scientific Opinion, Flavouring Group Evaluation 89, (FGE.89): Consideration of phenyl-substituted aliphatic tertiary alcohols and related aldehydes and esters evaluated by JECFA (63rd and 68th meetings) structurally related to aliphatic, alicyclic and aromatic saturated and unsaturated tertiary alcohols, aromatic tertiary alcohols and their esters evaluated by EFSA in FGE.18Revl (2009), 2009.

94. EFSA. Panel on Food Contact Materials Enzymes, Flavourings and Processing Aids (CEF), EFSA Scientific Opinion, Flavouring Group Evaluation 90, (FGE.90): Consideration of Aliphatic, acyclic and alicyclic terpenoid tertiary alcohols and structurally related substances evaluated by JECFA (68th meeting) structurally related to aliphatic, alicyclic and aromatic saturated and unsaturated tertiary alcohols, aromatic tertiary alcohols and their esters evaluated by EFSA in FGE.18Rev1 (2009), 2010.

95. EFSA. Panel on Food Contact Materials, Enzymes, Flavourings and Processing Aids (CEF), EFSA Scientific Opinion, Flavouring Group Evaluation 91, Revision 2 (FGE.91Rev2): Consideration of simple aliphatic and aromatic sulphides and thiols evaluated by the JECFA (53rd and 68th meetings) structurally related to aliphatic and alicyclic mono-, di-, tri-, and polysulphides with or without additional oxygenated functional groups evaluated by EFSA in FGE.08Rev5 (2012), 2014.

96. EFSA. Panel on Food Contact Materials Enzymes, Flavourings and Processing Aids (CEF), EFSA Scientific Opinion, Flavouring Group Evaluation 92, (FGE.92): Consideration of aliphatic acyclic diols, triols, and related substances evaluated by JECFA (68th meeting) structurally related to aliphatic primary and secondary saturated and unsaturated alcohols, aldehydes, acetals, carboxylic acids and esters containing an additional oxygenated functional group and lactones evaluated by EFSA in FGE.10Rev1 (2009)1, 2010.

97. EFSA. Panel on Food Contact Materials Enzymes, Flavourings and Processing Aids (CEF), EFSA Scientific Opinion, Flavouring Group Evaluation 93, Revision 1 (FGE.93Rev1): Consideration of sulphur containing heterocyclic compounds evaluated by JECFA (68th meeting) structurally related to thiazoles, thiophene, thiazoline and thienyl derivatives evaluated by EFSA in FGE.21Rev3, 2013.

98. EFSA. Panel on Food Contact Materials Enzymes, Flavourings and Processing Aids (CEF), EFSA Scientific Opinion, Flavouring Group Evaluation 94, Revision 2 (FGE.94Rev2): Consideration of aliphatic amines and amides evaluated in an addendum to the group of aliphatic and aromatic amines and amides evaluated by the JECFA (68th meeting), 2014. 
99. EFSA. Panel on Food Contact Materials Enzymes, Flavourings and Processing Aids (CEF), EFSA Scientific Opinion, Flavouring Group Evaluation 95, (FGE.95): Consideration of aliphatic, linear or branched-chain saturated and unsaturated alcohols, aldehydes, acids and related esters evaluated by JECFA (69th meeting) structurally related to esters of branched- and straightchain aliphatic saturated primary alcohols and of one secondary alcohol, and branched- and straight-chain unsaturated carboxylic acids evaluated by EFSA in FGE.05Rev1 (2008), 2010.

100. EFSA. Panel on Food Contact Materials, Enzymes, Flavourings and Processing Aids (CEF), EFSA Scientific Opinion, Flavouring Group Evaluation 96, (FGE.96): Consideration of 88 flavouring substances considered by EFSA for which EU production volumes / anticipated production volumes have been submitted on request by DG SANCO Addendum to FGE. 51, 52, 53, 54, 56, 58, 61, 62, 63, 64, 68, 69, 70, 71, 73, 76, 77, 79, 80, 83, 84, 85 and 87., 2011.

101. EFSA. Panel on Food Contact Materials, Enzymes, Flavourings and Processing Aids (CEF), EFSA Scientific Opinion, Flavouring Group Evaluation 98, (FGE.98): Consideration of three ring-unsaturated delta-lactones, 2011.

102. EFSA. Panel on Food Contact Materials, Enzymes, Flavourings and Processing Aids (CEF), EFSA Scientific Opinion, Flavouring Group Evaluation 99, (FGE.99): Consideration of furanone derivatives evaluated by the JECFA (63rd, 65th and 69th meetings), 2012.

103. EFSA. Minutes of the 26th plenary meeting of the scientific panel on food additives, flavourings, processing aids and materials in contact with food. Parma, 27-29 November 2007.

104. WHO. Food Additives Series 67, Safety evaluation of certain food additives and contaminants, prepared by the 76th meeting of the Joint FAO/WHO Expert Committee on Food Additives, Geneva, 5-14 June 2012, WHO, Geneva, 2012: Annex4: 319-31.

105. The Chemicals Society of Japan, Chemical Nomenclature, 2011. 